\title{
Job Characteristics and Off-Job Activities as Predictors of Need for Recovery, Well-Being, and Fatigue
}

\author{
Sabine Sonnentag \\ University of Konstanz
}

\author{
Fred R. H. Zijlstra \\ University of Surrey
}

\begin{abstract}
Two empirical studies examined need for recovery (i.e., a person's desire to be temporarily relieved from demands in order to restore his or her resources) as a mediator in the relationship between poor job characteristics (high job demands, low job control) and high off-job demands, on the one hand, and fatigue and poor individual well-being, on the other hand. Multilevel data from a daily survey study in the health service sector (Study 1) showed that high job demands, low job control, and unfavorable off-job activities predicted a high need for recovery. Need for recovery in turn was negatively related to individual well-being. A large-scale survey with a representative sample of the Dutch working population (Study 2) confirmed these findings for fatigue. In both studies, need for recovery mediated the effects of job characteristics and off-job activities on fatigue and poor well-being, respectively.
\end{abstract}

Keywords: recovery, recuperation, fatigue, health, well-being

Most psychological research on health and well-being has focused on the negative effects of stressors on health. However, the process of recovering from stressors is equally important and is increasingly getting more attention (Kuiper, van der Beek, \& Meijman, 1998; Steptoe, Lundwall, \& Cropley, 2000). Respite experiences and recovery processes have a positive effect on individual well-being (Etzion, Eden, \& Lapidot, 1998; Westman \& Eden, 1997; Westman \& Etzion, 2001) and on work engagement and proactive work behavior (Sonnentag, 2003). Moreover, several researchers have referred to lack of recovery when explaining why work stressors translate into poor well-being and health problems (Geurts, Kompier, Roxburgh, \& Houtman, 2003; Meijman \& Mulder, 1998; Sluiter, van der Beek, \& Frings-Dresen, 1999). Specifically, empirical research has shown that need for recovery (i.e., a person's desire for being - temporarily—relieved from exposure to stressors in order to replenish his or her resources) is a strong predictor of impaired well-being (Sluiter et al., 1999) and high employee turnover (de Croon, Sluiter, Blonk, Broersen, \& Frings-Dresen, 2004).

Sabine Sonnentag, Department of Psychology, University of Konstanz, Konstanz, Germany; Fred R. H. Zijlstra, Department of Psychology and Surrey Sleep Research Centre, University of Surrey, Surrey, United Kingdom.

The order of the authors is strictly alphabetical because both authors contributed equally to this article.

We are grateful to Sabine Pieh for collecting data for Study 1; to Merel van der Mast, Suzanne van Helvoirt, and Marieke Megens for their assistance with collecting the data for Study 2; and to Chris Fife-Schaw for his help with the structural equation modeling.

Correspondence concerning this article should be addressed to Sabine Sonnentag, Department of Psychology, University of Konstanz, Postbox D42, D-78457 Konstanz, Germany, or Fred R. H. Zijlstra, who is now at the Faculty of Psychology, University of Maastricht, P.O. Box 616, NL 6200 MD, Maastricht, The Netherlands. E-mail: sabine.sonnentag@unikonstanz.de or fred.zijlstra@psychology.unimaas.nl
Job characteristics impact on a person's need for recovery (de Croon et al., 2004; Sluiter, Frings-Dresen, van der Beek, \& Meijman, 2001; Sluiter et al., 1999). In this article, we extend the research on need for recovery and argue that not only factors stemming from one's job but also off-job experiences predict an individual's need for recovery and-in turn-individual strain reactions. In two empirical studies we examine the joint effects of job characteristics and off-job experiences on individuals' need for recovery, fatigue, and well-being. Moreover, we argue that need for recovery mediates the effects of job characteristics and off-job experiences on feelings of fatigue and well-being.

\section{The Concept of Need for Recovery}

Exposure to demands means that activity is required and that effort has to be expended in order to meet those demands. Effort expenditure draws on an individual's resources (Hockey, 1996; Zijlstra, 1996) and may lead to depletion of resources. The more demanding the situation, the higher (or longer lasting) the required level of activity, and the more resources will be consumed. This effort expenditure results in fatigue and is noticeable in physiological responses and in disturbances of mood (Meijman, 1991). Continuous depletion of resources will lead to negative load effects (e.g., fatigue) and, ultimately, in the absence of recovery, to exhaustion, losses of function, and physical and mental impairment. Exhaustion of resources can have negative consequences for an individual's health and well-being (Maslach, Schaufeli, \& Leiter, 2001). To prevent exhaustion of their resources, individuals need to regulate their effort expenditure. An important aspect of such regulation is that from time to time people have to replenish their resources, for example, by taking a break, that is, by beingtemporarily-relieved from the demands imposed on them (Meijman, 1991; Meijman \& Mulder, 1998). Under normal conditions, psychobiological systems return to baseline levels when stressors are absent. During this process of unwinding - also known as recovery - the organism returns to prestressor levels of functioning, and the prestressor homeostasis of physiological and psycho- 
logical systems is restored (Craig \& Cooper, 1992; Linden, Earle, Gerin, \& Christenfeld, 1997). Typically, this process takes place in the after-work period, usually the evening. Empirical evidence suggests that the more intensive the working day has been, the longer it takes to unwind in the evening (Frankenhauser, 1981; Meijman, Mulder, Van Dormolen, \& Cremer, 1992; Totterdell, Spelten, Smith, Barton, \& Folkard, 1995). The effects of intensive working days are still observable the following morning, as was demonstrated in a field experiment in which the intensity of the working day was manipulated (Meijman et al., 1992). People with intensive working days had more difficulty unwinding in the evening and had higher levels of adrenaline excretion at 10 p.m. The next morning, these people reported more sleep complaints and higher levels of fatigue and lower well-being than did other groups. Evidently, the recovery process had not been completed.

Fatigue and recovery are related concepts, but they are not identical: Fatigue is the state that results from being active in order to deal with the work demands, and recovery is the process of replenishing depleted resources or rebalancing suboptimal systems. When fatigue builds up, people feel a sense of urgency to take a break from the demands. This sense of urgency refers to the need for recovery that people feel. For physical activities, such as running, this is quite obvious: When people get tired, they want to stop running and take a rest. Also, mentally demanding activities can make people long to have a break, implying a need to stop thinking about the task at hand.

Need for recovery is conceived as a conscious emotional state characterized by a temporal reluctance to continue with the present demands or to accept new demands. It is associated with a wish for low baseline activity (Craig \& Cooper, 1992) and with the expectation that such a break is necessary in order to be able and willing to confront future demands. Need for recovery refers to a very early stage of a long-term strain process. Jansen, Kant, and van den Brandt (2002) described need for recovery as a "precursor of prolonged fatigue or psychological distress" (p. 324). There is empirical evidence that need for recovery and fatigue are distinct—although related-concepts (Jansen et al., 2002). Typically, need for recovery is experienced as "feelings of "wanting to be left in peace for a while,' or 'wanting to lay down for a while", (Sluiter et al., 2001, p. 29). In everyday situations, individuals express their need for recovery as a desire "to recharge the batteries." Thus, the availability of time and the opportunity to evade particular demands are essential components of the need for recovery concept. In optimal circumstances, individuals will satisfy their need for recovery by either taking a rest or engaging in appropriate leisure time activities. Preferably, such activities should not put similar or additional demands on the individual but should help him or her to disengage from work. In such an optimal situation an individual can unwind. Unwinding helps to replenish the resources and allows the need for recovery to be fulfilled. Consequently the individual will be fit for work again. However, particularly after a highly demanding working day, individuals may have reached a high activity level (implying high levels of arousal) and consequently have used up many of their resources. In those situations, need for recovery will be higher, and individuals will need more time for the recovery process. Various recent developments such as the use of mobile information and communication technology and the globalization of the economy have affected the traditional working pattern (Zijlstra, Schalk, \& Roe, 1996). These changes are likely to have an effect on the availability of time for recovery or, in other words, on the cycle of work and rest (Konradt, Schmook, \& Mälecke, 2000). Need for recovery can endure beyond the immediate off-work situation, and when recovery is not sufficient individuals may start the subsequent workday still experiencing a high need for recovery. Thus, we use a relatively broad concept of need for recovery and conceptualize it as the subjective experience of longing for relief from regular demands and for having some time that allows for low baseline activity.

\section{Predictors of Need for Recovery}

Sluiter et al. (1999) proposed a model that links job characteristics to need for recovery and health complaints. Specifically, they suggested that unfavorable job characteristics such as high job demands and low job control increase an individual's need for recovery, which in turn has an impact on health complaints. We argue that requirements from the nonwork domain also impose demands on people, in particular on dual-earner and single-parent families (Bekker, de Jong, Zijlstra, \& van Landeghem, 2000; Frone, Russell, \& Cooper, 1991; Geurts et al., 2003; Grandey \& Cropanzano, 1999; Grzywacz \& Marks, 2000). Therefore, we assume that off-job demands (stemming from household and care responsibilities) also contribute to an individual's need for recovery, fatigue, and poor well-being. We extend Sluiter et al.'s (1999) model by adding activities pursued during off-job time as additional predictors of need for recovery, fatigue, and poor wellbeing. Our conceptual model is displayed in Figure 1.

\section{Job Demands and Job Control as Predictors of Need for Recovery}

Job demands refer to stressful and strain-evoking work situations. Typical job demands include working under time pressure, role ambiguity, situational constraints, and long working hours. The effects of job demands on individuals are well documented (for reviews, see Kahn \& Byosiere, 1992; Sonnentag \& Frese, 2003). For example, when experiencing a high degree of job demands, individuals react with fatigue symptoms including disturbed mood and impaired cognitive functioning (Jones \& Fletcher, 1996; Meijman, 1991; Repetti, 1993; Zohar, 1999). To reduce these negative reactions and to avoid negative consequences in the long run, individuals need recovery (Frankenhauser, 1981; Meijman \& Mulder, 1998; Meijman et al., 1992). Therefore, one can assume that individuals who have been exposed to highly demanding work situations experience a higher need for recovery than individuals who have not been exposed to these situations. Our first hypothesis is that job demands are positively related to need for recovery (Hypothesis 1).

We propose that in addition to job demands, job control will also be related to need for recovery. Job control implies that one can, to a certain extent, determine when to take a break and decide on one's own working method and strategy (Jackson, Wall, Martin, \& Davids, 1993). In cases of high job control, individuals can switch to less demanding tasks and working methods when they feel overtaxed. However, when job control is low, individuals have no opportunity to escape from demanding tasks and have to continue to exert a high level of effort. As a consequence, need for recovery 


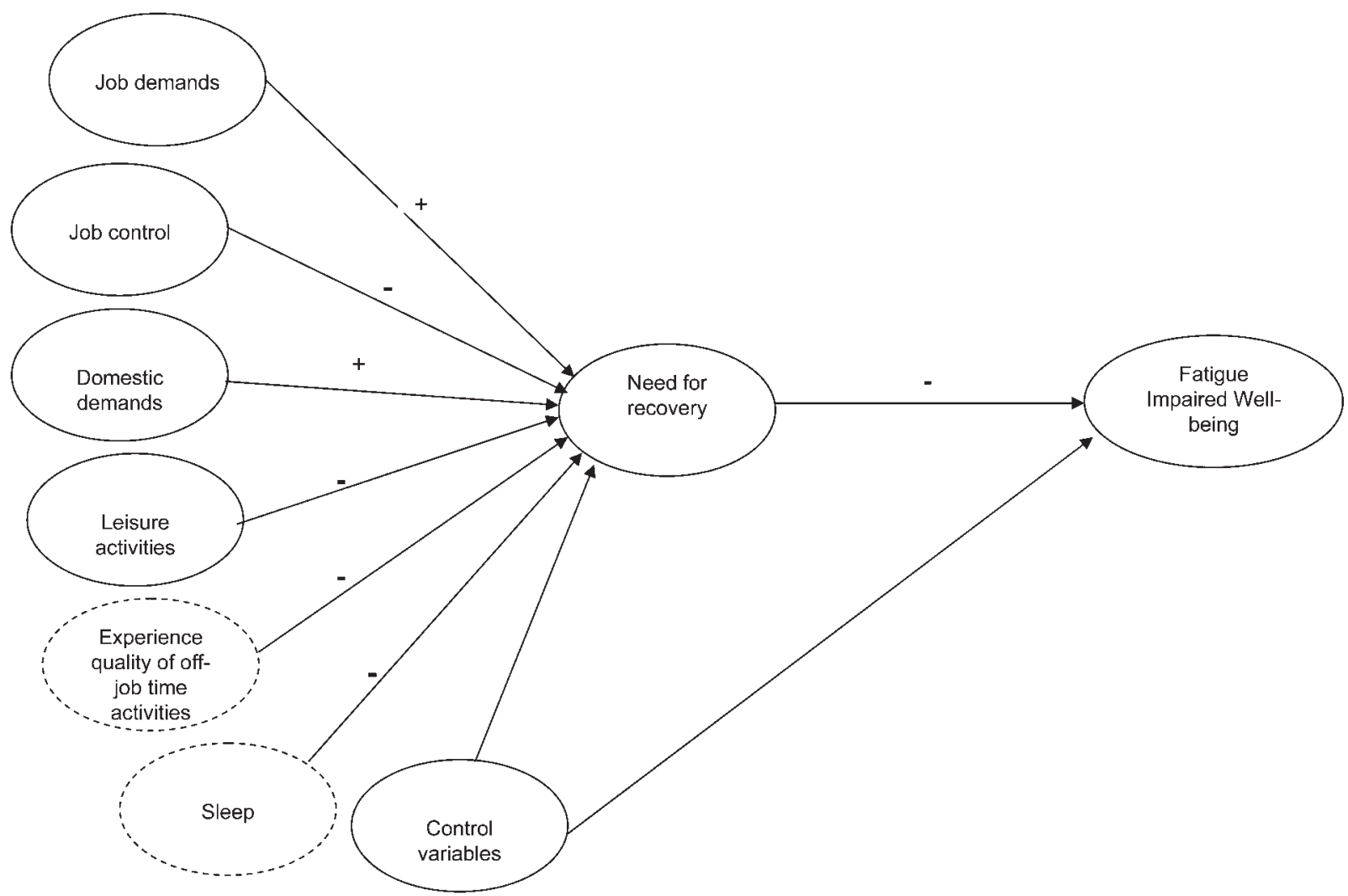

Figure 1. Conceptual model of need for recovery. Experience quality of off-job-time activities was measured only in Study 1; sleep was measured only in Study 2.

increases. Thus, we predict that job control is negatively related to need for recovery (Hypothesis 2).

\section{Off-Job Activities as Predictors of Need for Recovery}

We assume that not only job characteristics but also experiences during off-job time will have an effect on need for recovery. Specifically, we are interested in the types of activities pursued during off-job time and the experience quality associated with these off-job activities as predictors of need for recovery. Time spent outside the workplace must not be equated with leisure time because this time cannot be completely allocated to freely chosen and potentially recovering activities (Iso-Ahola, 1997). In addition to time needed for personal maintenance (i.e., sleeping, eating, personal hygiene), time has to be spent on household (domestic demands) or even on job-related tasks. In a study on recovery processes in schoolteachers, Sonnentag (2001) differentiated between various types of off-job activities: (a) job-related and other task-related activities, (b) household and child-care activities, and (c) leisure activities comprising low-effort activities, social activities, and physical activities. Typical examples of job-related activities include activities such as completing a task for one's job or preparing for the following day. Other task-related activities refer to administrative duties relating to one's private life, such as paying bills or completing one's taxes. Job-related and other task-related activities draw on resources similar to those already called upon during working time (Craig \& Cooper, 1992). Con- tinuous drawing on the same resources further increases the strain process and hence the need for recovery. Therefore, we hypothesize that the amount of time spent on job-related and other taskrelated activities is positively related to need for recovery (Hypothesis 3).

Household and child-care activities also require effort and can be particularly fatiguing (Bekker et al., 2000; Frone, Russell \& Cooper, 1997; Lundberg, Marberg, \& Frankenhauser, 1994). When people engage in demanding household and child-care activities after coming home from work, resources are not restored and therefore no recovery occurs. This implies that these activities draw additionally on an individual's resources. Therefore, we expect that the amount of time spent on household and child-care activities is associated with a higher need for recovery (Hypothesis 4).

Leisure activities primarily include activities such as low-effort activities, social activities, and physical activities. Low-effort activities such as watching TV or taking a bath by definition put no or only few demands on the individual. As they do not require much effort, they do not draw on the resources required at one's job but rather allow for the restoration of these resources. Therefore, we assume that they have a recovering effect and hence will reduce an individual's need for recovery. Social activities comprise activities that focus on social contact and provide the opportunity for social support. Social support is a highly important external resource that helps in restoring other resources (Hobfoll, 1998). Although physical activities (e.g., sports, exercise) do re- 
quire effort, they draw on capacities and resources different from those required in most jobs. Because people are using different resources, the original resources are not further depleted, and the need for recovery is not enhanced. There may even be an opportunity to replenish the original resources and thus contribute to recovery. We hypothesize that the amount of time spent on leisure activities, taken together, is negatively related to need for recovery (Hypothesis 5).

We assume that in addition to the time spent on specific activities during off-job time, the experience quality associated with off-job activities has an effect on need for recovery. Experience quality refers to the degree to which an individual perceives off-job activities as positive and pleasurable. Exposure to high job demands results in fatigue associated with impaired mood (e.g., Jones \& Fletcher, 1996; Zohar, 1999). Therefore, the need for recovery experienced by a strained individual also implies the desire to improve his or her mood. Research on mood regulation has shown that individuals try to improve their mood by pursuing pleasant activities (Thayer, Newman, \& McClain, 1994) and that actual engagement in pleasant activities does indeed improve mood (Totterdell \& Parkinson, 1999). Empirical studies on vacations suggest that individuals who experience such a recovery period as a positive and satisfying event enjoy a higher degree of recovery than individuals who do not (Lounsbury \& Hoopes, 1986; Westman \& Eden, 1997). As a consequence, the remaining need for recovery will be relatively low. Therefore, we hypothesize that positive experience quality is negatively related to need for recovery (Hypothesis 6).

One might argue that specific off-job activities and positive experience quality are not equally important in all situations. More specifically, leisure activities and positive experience quality might be most beneficial when an individual is facing high job demands, whereas job-related as well as household and child-care activities show particularly strong relationships with need for recovery when individuals are confronted with high job demands. This would imply an interactive effect between job demands and off-job activities in predicting need for recovery, fatigue, and poor well-being. Alternatively, one might argue that need for recovery is primarily determined by the level of effort expenditure caused by physical and/or mental effort. For our model, we adopted the energy expenditure approach (Hockey, 1996; Zijlstra, 1996). Although different demands tap different capacities and functions (and resources), they all require a certain amount of effort. The lower the demands, the lower the level of effort expenditure, but effort expenditure can never be negative. Even when other resources are used (i.e., change of activity), to allow the original resources to be replenished, effort is expended. Therefore, it is also plausible to assume simple additive effects of job demands and off-job activities in predicting need for recovery, fatigue, and poor well-being. To gain more insight into the relative importance of off-job activities in situations with high versus low job demands, we examine interaction effects between off-job activities and job demands on an exploratory basis.

\section{Need for Recovery, Fatigue, and Impaired Well-Being}

Working results in strain reactions such as fatigue and impaired well-being. Spending time on recovery can alleviate these strain reactions (Craig \& Cooper, 1992; Meijman \& Mulder, 1998).
Thus, when people are sufficiently recovered and not experiencing a desire for further recovery, their level of fatigue will diminish, and their well-being will increase. However, when recovery has been insufficient and people still feel the need for more recovery in order to arrive at the predemand state, there might be cumulating effects of residual fatigue that will lead to reduced well-being (Steptoe et al., 2000). In their cross-sectional study on drivers, Sluiter et al. (1999) found significant effects of need for recovery on psychosomatic complaints and emotional exhaustion when controlling for a number of other variables (e.g., work hours per week, perceived load). Therefore, we hypothesize that need for recovery is related to fatigue and to impaired well-being (Hypothesis 7).

In addition, we assume that need for recovery mediates the effects of job demands, job control, and off-job activities on fatigue and impaired well-being. Geurts et al. (2003) argued that the relationship between workload and health complaints might best be understood as an indirect relationship, with work-home interference as the "crucial intervening pathway," and they suggested that a high workload exerts negative effects in the nonwork domain. These negative effects are experienced as interference between work and home and prohibit opportunities for recovery. Insufficient recovery will leave individuals with a high need for recovery, and if recovery is insufficient, fatigue will increase and may lead to exhaustion, with negative consequences for well-being.

Furthermore, the pursuit of activities with a high duty profile during off-job time (i.e., work-related activities as well as household and child-care activities) further impedes recovery. Thus, after having pursued such activities, an individual will continue to experience need for recovery, fatigue will remain high, and wellbeing will be impaired. Leisure activities, such as low-effort activities, physical activities, and social activities, however, will not impose additional demands (or at least will impose a different type of demands) and therefore will not increase the individual's need for recovery. Such leisure activities may even facilitate recovery. Through the recovery process, fatigue will be reduced and wellbeing will increase again. Recent studies provide empirical evidence that processes related to recovery indeed play a mediating role in the relationship between unfavorable work situations and poor well-being (Geurts et al., 2003; Sluiter, de Croon, Meijman, \& Frings-Dresen, 2003; Sluiter et al., 1999). Therefore, we propose that need for recovery mediates the effects of job demands, job control, and off-job activities on fatigue and well-being (Hypothesis 8).

\section{Overview of the Studies}

We tested our hypotheses in two separate studies with different methodological approaches and samples. Need for recovery was also operationalized differently in both studies. Study 1 used daily survey data obtained from a professionally homogeneous sample and tested within-person effects. Need for recovery was operationalized in terms of needing an opportunity to recover, and wellbeing was used as the outcome measure. Employees in the health care sector completed daily surveys over a period of 5 working days and reported off-job activities, need for recovery, and wellbeing. In Study 2, we used survey data from a large representative sample of the Dutch working population. Participants in this study came from a broad range of different professional backgrounds. 
Need for recovery was operationalized in terms of symptoms indicating the intensity of the need, and fatigue was our core outcome variable. When analyzing these data, we were interested in between-person effects.

Study 1

\section{Method}

\section{Sample}

The sample comprised 96 health service employees working in general and psychiatric hospitals in Germany. Health service jobs are characterized by a high degree of job demands, such as high workload and high time pressure (Houtman \& Kompier, 1995). In addition, health service employees are at risk of impaired psychological well-being (Baldwin, 1999; Firth-Cozens, 1999). Therefore, recovery and the protection of well-being are a core issue for health service professionals. Seventy-six percent of the participants were women, and $24 \%$ were men. Participants' mean age was 33.9 years $(S D=9.6)$. Of the 96 participants, 25 were physicians, 59 were nurses ( 3 of them in a supervisory position), and 12 were trainee nurses. Average job tenure was 9.5 years $(S D=8.4)$. Most of the participants $(69.5 \%)$ were married or were living with a partner; $30.5 \%$ were living alone. In total, $72.6 \%$ of the participants had no children, $12.6 \%$ had one child, $11.6 \%$ had two children, and $3.2 \%$ had three children.

\section{Measures}

We used a questionnaire and a daily survey for data collection. All items were in German. Participants had to complete the questionnaire before they started to fill in the daily survey, which covered 5 work days. Each day, participants were asked to respond to items on two occasions: (a) when returning home from work and (b) before going to bed. Means, standard deviations, and zero-order correlations among all variables are displayed in Table 1

Job demands. We assessed three aspects of job demands: (a) time pressure, (b) situational constraints, and (c) hours of overtime. We measured time pressure and situational constraints with the questionnaire by using scales developed by Semmer (1984) and Zapf (1993). Previous studies showed acceptable to good validity coefficients for these scales (for a summary, cf. Semmer, Zapf, \& Dunckel, 1999). Specifically, we measured time pressure with five items referring to high quantitative workload (e.g., "How often do you work under time pressure?"; Cronbach's $\alpha=$ .83). We assessed situational constraints with five items referring to problems caused by missing or defective equipment and tools or by missing or outdated information (Cronbach's $\alpha=.70$ ). We measured hours of overtime in the daily survey at the second measurement occasion. On each of the 5 work days on which the participants completed the daily survey, they reported how many hours of overtime they had worked on that specific day.

Job control. For assessing job control, we used a scale developed by Semmer (1984) and Zapf (1993). Participants responded to five items in the questionnaire (e.g., "To what extent can you determine how you do your work?"; Cronbach's $\alpha=.71$ )

Off-job activities. We assessed time-related and quality-related aspects of off-job activities. We measured all these variables on a daily basis with the daily survey. Participants answered all items referring to off-job activities at the second measurement occasion before they went to bed. More specifically, we first provided participants with short descriptions of five activity categories and a list of prototypical activities within each category that was developed in an earlier study (Sonnentag, 2001). Activity categories included (a) work-related activities (e.g., finishing or preparing for work duties and doing one's private administrative tasks); (b) household and child-care activities (e.g., cooking, doing the dishes, shopping, taking care of the children); and various leisure activities, namely (c) low-effort

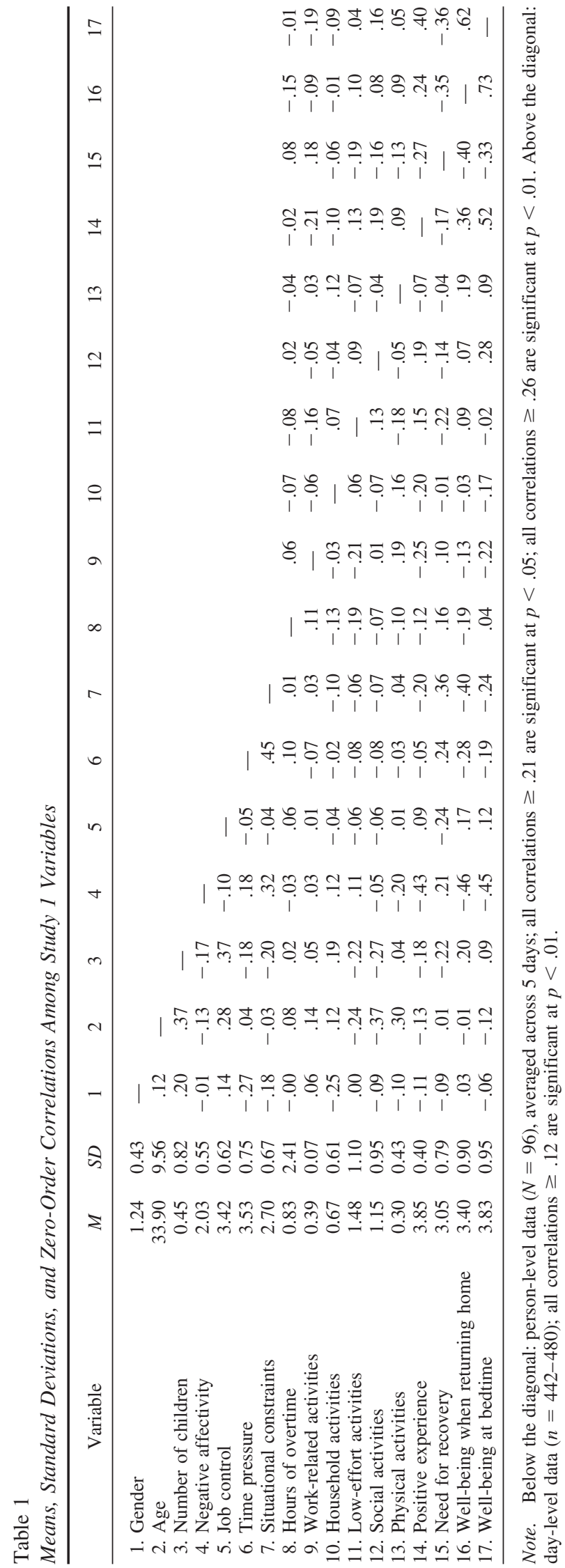


activities (e.g., watching TV, taking a bath); (d) social activities (e.g., meeting with others, making a phone call in order to chat); (e) physical activities (e.g., sports, cycling). For all five activity categories, we asked participants whether they had pursued this type of activity on that day. If they answered "no," they were asked to proceed to the items referring to the next activity category. If they answered "yes," they were asked to respond to time-related and quality-related items.

The time-related aspects of off-job activities were assessed as follows: For each activity category, participants reported how much time they had spent on that type of off-job activity during that specific day. Thus, for each of the 5 days we obtained five variables (one for each activity category).

The quality-related aspect of off-job activities referred to the positive experience of the off-job activities pursued. For each activity category performed in the specific day, participants were asked to respond to the following three items on a 5-point Likert scale: (a) "Pursuing these activities was a positive experience for me"; (b) "Performing these activities made me feel good"; and (c) "I was in a good mood after pursuing these activities." For work-related activities, Cronbach's alphas for this experience-quality measure computed separately for the 5 days ranged between .72 and $.90(M=.82)$. For household activities, Cronbach's alphas ranged between .82 and $.88(M=.85)$. For low-effort activities, Cronbach's alphas ranged between .65 and $.86(M=.81)$. For social activities, Cronbach's alphas ranged between .83 and $.89(M=.85)$. For physical activities, Cronbach's alphas ranged between .83 and $.89(M=$ .86).

For further analysis, we computed a mean experience-quality score for each of the 5 days by averaging the ratings provided for the five activity categories across all activities a person had performed on a specific day. Thus, for each of the 5 days we obtained one score for each participant. As only a very few participants performed all five activities on a single day, we could not compute the usual Cronbach's alpha coefficient for this mean experience-quality score. Instead, we correlated the ratings provided separately for the five activities with this mean experience-quality score. The correlation between the experienced quality of work-related activities and the mean experience-quality score-computed separately for each of the 5 days-ranged between .52 and $.69(M=.60)$. For household activities, this correlation ranged between .63 and $.76(M=.70)$; for low-effort activities, it ranged between .59 and $.74(M=.67)$; for social activities, it ranged between .59 and $.76(M=.69)$; and for physical activities, it ranged between .36 and $.63(M=.53)$. These correlations correspond to satisfying to good item-total correlations.

Need for recovery. Participants reported their need for recovery in the daily survey at the second measurement occasion before they went to bed. On each of the 5 days, they responded to a 2 -item scale focusing on the time component of need for recovery: (a) "Today I would have needed more time for relaxing and recovering from work" and (b) "Considering the total of all activities that I pursued after work, I have had enough time to relax and to recover from work today" (recoded). Cronbach's alphas computed separately for the 5 days ranged between .80 and $.88(M=.83)$.

Well-being at bedtime. Participants indicated their well-being in the daily survey at the second measurement occasion immediately before they went to bed. On each of the 5 days, they reported their present state with respect to four items of the "low tension" scale developed by Nitsch (1976) and revised by Apenburg (1986): (a) "calm," (b) "easygoing," (c) "wellbalanced," (d) "laid-back." Cronbach's alphas computed separately for the 5 days ranged between .90 and $.95(M=.93)$. To avoid an effect of filling in the daily survey on the well-being measure, we had participants respond to these well-being items before they answered the questions on their off-job activities.

To test whether (low) need for recovery and well-being represent two distinct constructs, we ran a set of exploratory factor analyses with varimax rotation. For each of the 5 days, a separate factor analysis was run. Analyses showed two-factor solutions for all 5 days, with need-for- recovery items loading on the first factor and well-being items loading on the second factor.

Control variables. As need for recovery and well-being at bedtime might be affected not only by job characteristics and off-job activities, in our analyses we controlled for a number of additional variables (gender, age, number of children, negative affectivity, and well-being when returning home from work). We controlled for dispositional negative affectivity in the analyses because negative affectivity may account for shared variance between our predictor variables, on the one hand, and need for recovery and well-being, on the other hand (Burke, Brief, \& George, 1993). Specifically, we measured negative affectivity with the 10 negative affect items from the Positive and Negative Affect Schedule (PANAS; Watson, Clark, \& Tellegen, 1988). Cronbach's alpha was .84. We controlled for well-being when returning home from work because well-being at bedtime and need for recovery at the end of the day may be largely influenced by well-being after work. Therefore, our analyses provide a strong test of our hypotheses because we examined the effects of job characteristics and off-job activities and experience quality that go beyond the effects of well-being when coming home from work. We assessed participants well-being when returning home from work in the daily survey at the first measurement occasion, as soon as participants came home from work Participants were asked to indicate their momentary state on a 4-item scale. The items were identical to the items used to measure well-being at bedtime. Cronbach's alpha computed separately for the 5 days ranged between .81 and $.94(M=.90)$. We used one-item measures for assessing gender, age, and number of children.

\section{Data Analysis Procedure}

Our data set comprised data at the person level (Level 2; demographic variables, time pressure, situational constraints, job control, and negative affectivity) and at the day level (Level 1; hours of overtime, well-being when returning home form work, well-being at bedtime, and need for recovery). Day-level data were nested within the person-level data. Because of this hierarchically organized data structure, we analyzed our data with a multilevel approach, also known as hierarchical linear modeling (Bryk \& Raudenbush, 1992). This approach allows for dependent observations within the higher level data structure (Snijders \& Bosker, 1999). We used the MLn program for data analysis (Rasbash \& Woodhouse, 1996). We centered predictor variables at the person level around the grand mean and predictor variables at the day level around the respective person mean. Centering day-level variables around the person mean was necessary in order to analyze day-specific effects within persons (cf. Hofmann \& Gavin, 1998).

\section{Results}

We followed a hierarchical data analysis strategy and examined a number of nested models. We started with a null model that included the intercept as the only predictor. In Model 1, we entered the control variables, specifically, demographic variables (gender, age, number of children, negative affectivity; Level 2) and wellbeing when returning home from work (Level 1). In Model 2, job demands (time pressure, situational constraints [both Level 2], and hours of overtime on that specific day [Level 1]) and job control (Level 2) were entered. In Model 3, the off-job activity variables (time spent on work-related activities, time spent on household activities, time spent on low-effort activities, time spent on social activities, time spent on physical activities, and experience quality [all Level 1]) were entered. To test interaction effects between job demands and off-job activities, we entered interaction terms between the three job demands variables (time pressure, situational constraints, and hours of overtime) and time- and quality-related 


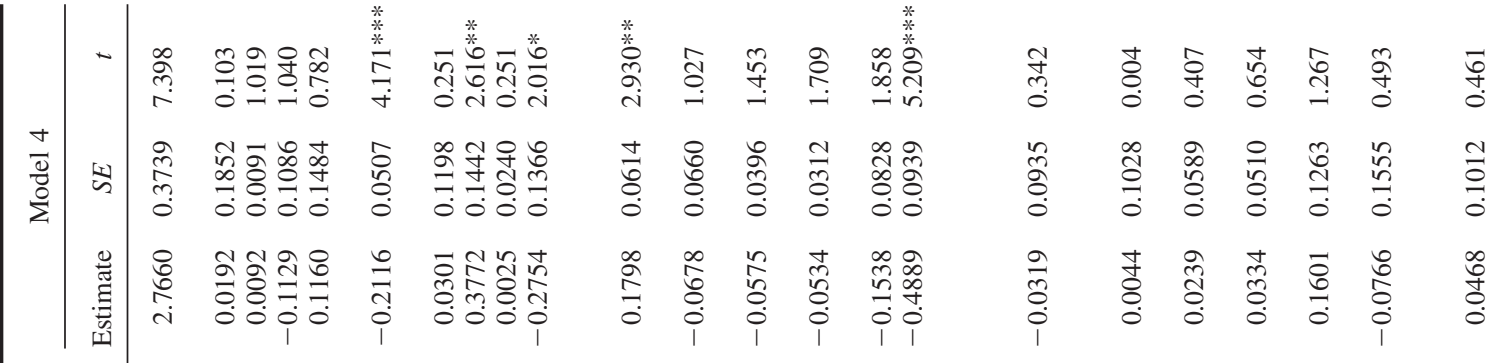

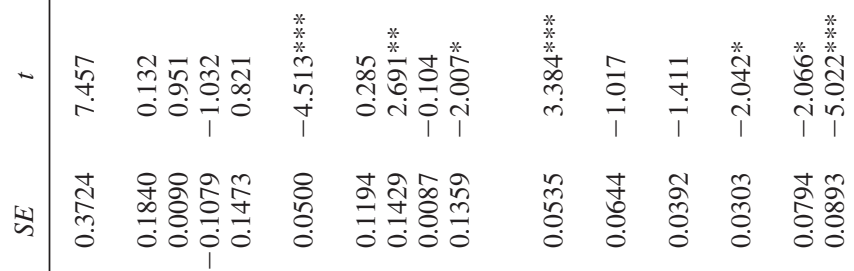

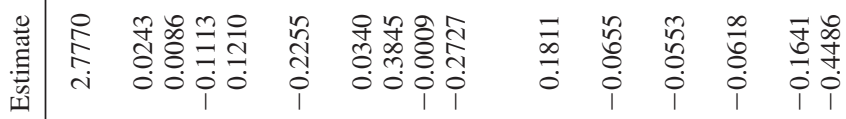

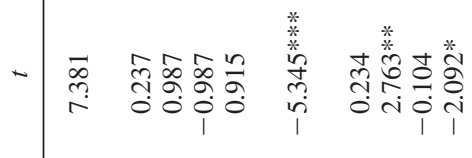

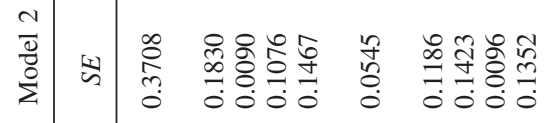

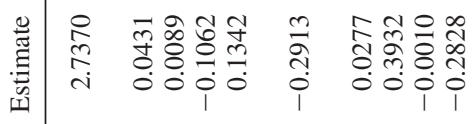

$$
\begin{aligned}
& \text { 一 }
\end{aligned}
$$

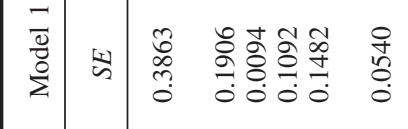

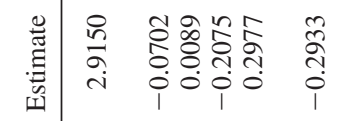

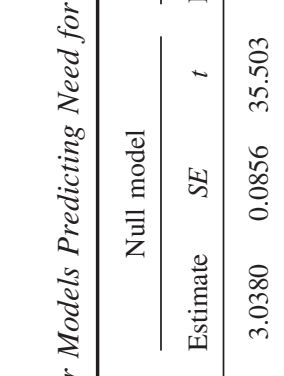

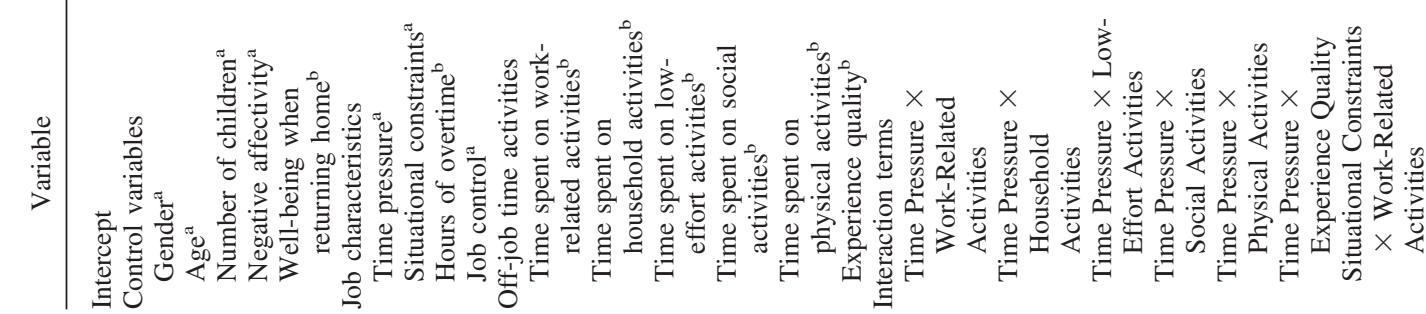




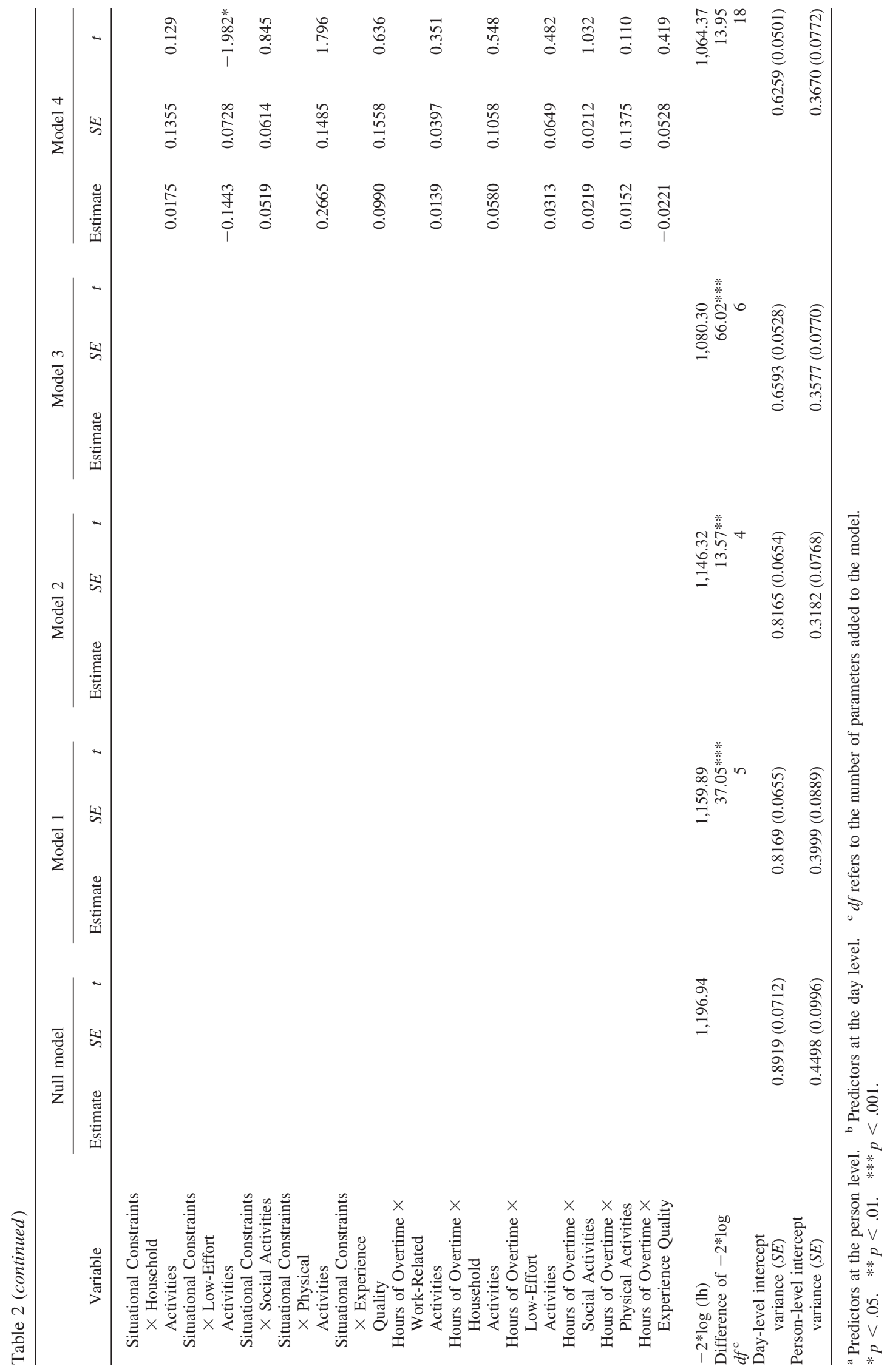


aspects of off-job activities in Model 4. We examined the improvement of each model over the previous one with a likelihood ratio difference test. Differences between likelihood ratios follow a chi-square distribution (with degrees of freedom equal to the number of new parameters added to the model).

Table 2 shows the results for need for recovery as the dependent variable. Analysis showed that Model 1, which included demographic variables, negative affectivity, and well-being when returning home from work, showed a significant improvement over the null model (difference of $-2 * \log =37.05 ; d f=5 ; p<.001$ ). Negative affectivity and well-being when returning home were significant predictors in this model.

To test the effects of job demands (Hypothesis 1) and job control (Hypothesis 2), we entered job demands and job control in Model 2. This model showed a significantly smaller likelihood ratio than Model 1 (difference of $-2 * \log =13.57$; $d f=4 ; p<$ .01 ), indicating that job demands and job control contributed to the prediction of need for recovery at bedtime-beyond the effect of negative affectivity and the particularly strong effect of well-being when returning home from work. Situational constraints and job control were significant predictors of need for recovery. Thus, Hypothesis 1 was partially supported, and Hypothesis 2 was fully supported.

To Test Hypotheses 3, 4, 5, and 6, we included off-job activity variables into Model 3. This model fit the data better than Model 2 (difference of $-2 * \log =66.02 ; d f=6 ; p<.001$ ). Inspection of regression coefficients showed that a high amount of time spent on work-related activities had a strong positive effect on need for recovery at bedtime, whereas high amounts of time spent on social activities and physical activities had negative effects on need for recovery. Experience quality had a strong negative effect on need for recovery. Time spent on household activities or low-effort activities had no effect. Thus, Hypotheses 3 and 6 were supported, and Hypothesis 5 was supported with respect to social and physical activities (not with respect to low-effort activities). Hypothesis 4 did not receive any support from the data. Taken together, our hypotheses were partially confirmed by the analysis: Individuals who face high situational constraints and low control at work, who spend much time on work-related activities at home, who spend little time on social or physical activities, and who do not feel that their off-job time is a positive experience report a higher need for recovery at bedtime.

In addition, we analyzed interaction effects between job demands and off-job activities by entering interaction terms between job demands and off-job activities (Model 4). Model 4, with the interaction terms, did not show a better model fit than Model 3 (difference of $-2 * \log =13.95 ; d f=18 ; n s$ ). Thus, the relationship between off-job activities and need for recovery was not moderated by job demands.

To examine the effect of need for recovery on well-being (Hypothesis 7), we tested an additional set of nested models with well-being at bedtime as the dependent variable. Again, we started with a null model. In Model 1, we entered the same control variables (gender, age, number of children, negative affectivity, well-being when returning home from work) as in the previous analysis. In Model 2, we entered need for recovery. The results are shown in Table 3 . Model 1, which included demographic variables, negative affectivity, and well-being when returning home from work, showed a significantly better fit to the data than did the null model (difference of $-2 * \log =103.54 ; d f=5 ; p<.001$ ). Negative affectivity and well-being when returning home from work were significant predictors. Analysis further showed that Model 2 fit the data better than did Model 1 (difference of $-2 * \log =31.19 ; d f=1 ; p<.001)$, indicating that need for recovery is a highly significant predictor of well-being at bedtime. When individuals experience a high need for recovery before going to bed, their well-being suffers. Thus, our data supported Hypothesis 7.

To test the mediator hypothesis (Hypothesis 8), we followed the procedure suggested by Baron and Kenny (1986) and a more direct test. According to Baron and Kenny, to demonstrate mediation, three conditions must be met: First, the presumed independent variables (job demands, job control, and off-job activities) must be related to the presumed mediator (need for recovery). Second, the

Table 3

Multilevel Estimates for Models Predicting Well-Being at Bedtime, From Need for Recovery

\begin{tabular}{|c|c|c|c|c|c|c|c|c|c|}
\hline & \multicolumn{3}{|c|}{ Null model } & \multicolumn{3}{|c|}{ Model 1} & \multicolumn{3}{|c|}{ Model 2} \\
\hline & Estimate & $S E$ & $t$ & Estimate & $S E$ & $t$ & Estimate & $S E$ & $t$ \\
\hline Intercept & 3.8780 & 0.0995 & 38.994 & 4.5530 & 0.4026 & 11.309 & 4.5680 & 0.4046 & 11.290 \\
\hline \multicolumn{10}{|l|}{ Control variables } \\
\hline Gender $^{\mathrm{a}}$ & & & & -0.1268 & 0.1989 & -0.638 & -0.1279 & 0.2000 & -0.640 \\
\hline $\mathrm{Age}^{\mathrm{a}}$ & & & & -0.0173 & 0.0098 & -1.763 & -0.0178 & 0.0098 & -1.812 \\
\hline Number of children ${ }^{a}$ & & & & 0.1596 & 0.1138 & 1.403 & 0.1649 & 0.1144 & 1.441 \\
\hline Negative affectivity ${ }^{\mathrm{a}}$ & & & & -0.7876 & 0.1545 & $-5.098 * * *$ & -0.7823 & 0.1553 & $-5.037 * * *$ \\
\hline Well-being when returning home $\mathrm{e}^{\mathrm{b}}$ & & & & 0.4767 & 0.0509 & $9.360 * * *$ & 0.3911 & 0.0506 & $7.726 * * *$ \\
\hline Need for recovery ${ }^{\mathrm{b}}$ & & & & & & & -0.2892 & 0.0504 & $-5.738 * * *$ \\
\hline$-2 * \log (\mathrm{lh})$ & & & 1233.75 & & & 1130.21 & & & 1099.02 \\
\hline Difference of $-2 * \log$ & & & & & & $103.54 * * *$ & & & $31.19 * * *$ \\
\hline$d f^{\mathrm{c}}$ & & & & & \multicolumn{2}{|r|}{5} & \multirow{2}{*}{\multicolumn{3}{|c|}{$\begin{array}{r}1 \\
06542(00524)\end{array}$}} \\
\hline Day-level intercept variance $(S E)$ & & \multicolumn{2}{|c|}{$0.9209(0.0738)$} & & 0.72 & $(0.0581)$ & & & \\
\hline Person-level intercept variance $(S E)$ & & \multicolumn{2}{|c|}{$0.6725(0.1333)$} & & \multicolumn{2}{|c|}{$0.4719(0.0964)$} & & \multicolumn{2}{|c|}{$0.4948(0.0973)$} \\
\hline
\end{tabular}

${ }^{\mathrm{a}}$ Predictors at the person level. ${ }^{\mathrm{b}}$ Predictors at the day level. ${ }^{\mathrm{c}} d f$ refers to the number of parameters added to the model.

$* * * p<.001$. 
presumed mediator (need for recovery) must be related to the presumed dependent variable (well-being at bedtime). Third, a previously significant relationship between the independent variable (job demands, job control, and off-job activities) and the dependent variable (well-being at bedtime) must no longer be significant when controlling for the mediator (need for recovery).

The analyses described above have shown that the first two conditions were met in this data set. To test the third condition, we performed an additional set of analyses with well-being at bedtime as the dependent variable. In a set of nested models, we first ran a null model. Then we entered the control variables into the model (Model 1), then job demands and job control (Model 2), and then off-job activities (Model 3). Finally, we entered need for recovery (Model 4). Table 4 shows the results. Findings from the comparison between the null model and Model 1 are identical to those from the analysis reported in Table 3, with low negative affectivity and well-being when returning home from work showing significant positive relationships with well-being at bedtime.

When we entered job demands and job control into Model 2, model fit did not improve significantly (difference of $-2 * \log =$ 4.22; $d f=4 ; n s)$. However, when we included off-job activities as predictor variables in Model 3, a better fit resulted (difference of $-2 * \log =22.36 ; d f=6 ; p<.01)$. A high amount of time spent on work-related activities was negatively related to well-being at bedtime. Experience quality showed a strong positive relationship with well-being at bedtime. The other off-job activity variables had no effect on well-being at bedtime.

After entering need for recovery in Model 4, we found that amount of time spent on work-related activities was no longer a significant predictor of well-being before going to sleep. Experience quality was still a significant predictor, but smaller in size than in the analysis without the mediator variable. The estimate for need for recovery was significant. Thus, this finding, based on the Baron and Kenny (1986) approach, indicates that need for recovery fully mediated the effect of work-related activities on well-being at bedtime. The effect of experience quality was partially mediated by need for recovery.

To test mediation more directly, we followed the procedure described by MacKinnon and Dwyer (1993), which is also applicable to multilevel data sets (Krull \& MacKinnon, 1999, 2001). For time spent on work-related activities, the analysis resulted in an estimate of $\beta_{a} * \beta_{b}$ of 0.04446 and a standard error $\left(\sigma_{\beta a \beta b}\right)$ of 0.01650 . The resulting $z$ statistic was significant $(z=2.69, p<$ $.05)$, indicating that need for recovery was a significant mediator in the relationship between time spent on work-related activities and well-being at bedtime. For experience quality, the estimate of $\beta_{a}{ }^{*} \beta_{b}$ was 0.11013 , with a standard error $\left(\sigma_{\beta a \beta b}\right)$ of 0.03307 , again resulting in a significant $z$ statistic $(z=3.33, p<.001)$. The results of this more direct method for testing mediation converged with the results attained by the Baron and Kenny (1986) method. Both methods showed that need for recovery mediated the effects of time spent on work-related activities and of positive experience quality on well-being at bedtime. However, no mediator effect was evident for job demands, job control, and the other off-job activities. Thus, Hypothesis 8 received partial support.

\section{Discussion}

Study 1 showed that job demands, particularly situational constraints, were positively related to need for recovery. Job control was negatively related to need for recovery. These findings support Hypotheses 1 and 2. Off-job activities were also associated with need for recovery. The various types of off-job activities appeared to have differential effects. Specifically, pursuing work-related activities during off-job time were positively related to need for recovery, whereas social and physical activities were negatively related to need for recovery. Household and child-care activities were unrelated to need for recovery. In addition, high experience quality was negatively related to need for recovery. Well-being at bedtime was predicted by time spent on work-related activities and low experience quality. The relationships between off-job activities and need for recovery were not contingent on the level of job demands. Well-being when coming home was the strongest predictor for well-being at bedtime. Need for recovery was positively related to low well-being at bedtime. Analysis further showed that need for recovery partially mediated the effects of off-job experiences on well-being, partially confirming Hypothesis 8 .

It is interesting that situational constraints, job control, and specific leisure time activities such as social and physical activities were related to need for recovery but not to well-being at bedtime. This finding suggests that the opportunity to recover (i.e., to regulate one's effort expenditure) is important for an individual's psychological functioning. Need for recovery appears to be a sensitive indicator for disturbances in this pattern at the day level. In addition, well-being at bedtime might be influenced by factors other than the primarily time-based measures of off-job activities.

Study 1 has some specific limitations. First, our results are based on a sample of physicians and nurses. It might be that the findings are specific to these professional groups, who face high job demands and often suffer from impaired psychological well-being. It remains an open question whether our findings generalize beyond this rather specific sample. Second, we investigated within-person variation of need for recovery and well-being. Thus, the study provided information about the predictors of day-specific fluctuations in need for recovery and well-being. However, betweenperson variations of need for recovery and well-being were not addressed in this study. Third, Study 1 focused on job demands, job control, and off-job experiences as predictors of need for recovery and well-being. However, one can think of additional factors that might be relevant. One might assume that the amount of sleep is also an important predictor of need for recovery (Pressman \& Orr, 1997). For example, it might be that sleep at night compensates for insufficient recovery during evening hours. This might imply that in the long run, it is not off-job activities that are most relevant for recovery and well-being but factors associated with sleep. Therefore, as an additional hypothesis we propose that time for sleep will be negatively related to need for recovery (Hypothesis 5a).

Study 1 demonstrated support for some of our hypotheses, and in particular, the mediation hypothesis was partly supported. Confirmation of the results in a second study might provide more conclusive evidence in support of our hypotheses. Therefore, in the second study, we used data from a large cross-sectional survey among a representative sample of the Dutch working population. The advantage of doing so was that some of the specific limitations of Study 1 could be overcome. Using different instruments and operationalizations for some key concepts would contribute to the robustness of the findings by demonstrating that they are not dependent on a specific way of operationalizing the concepts. In 


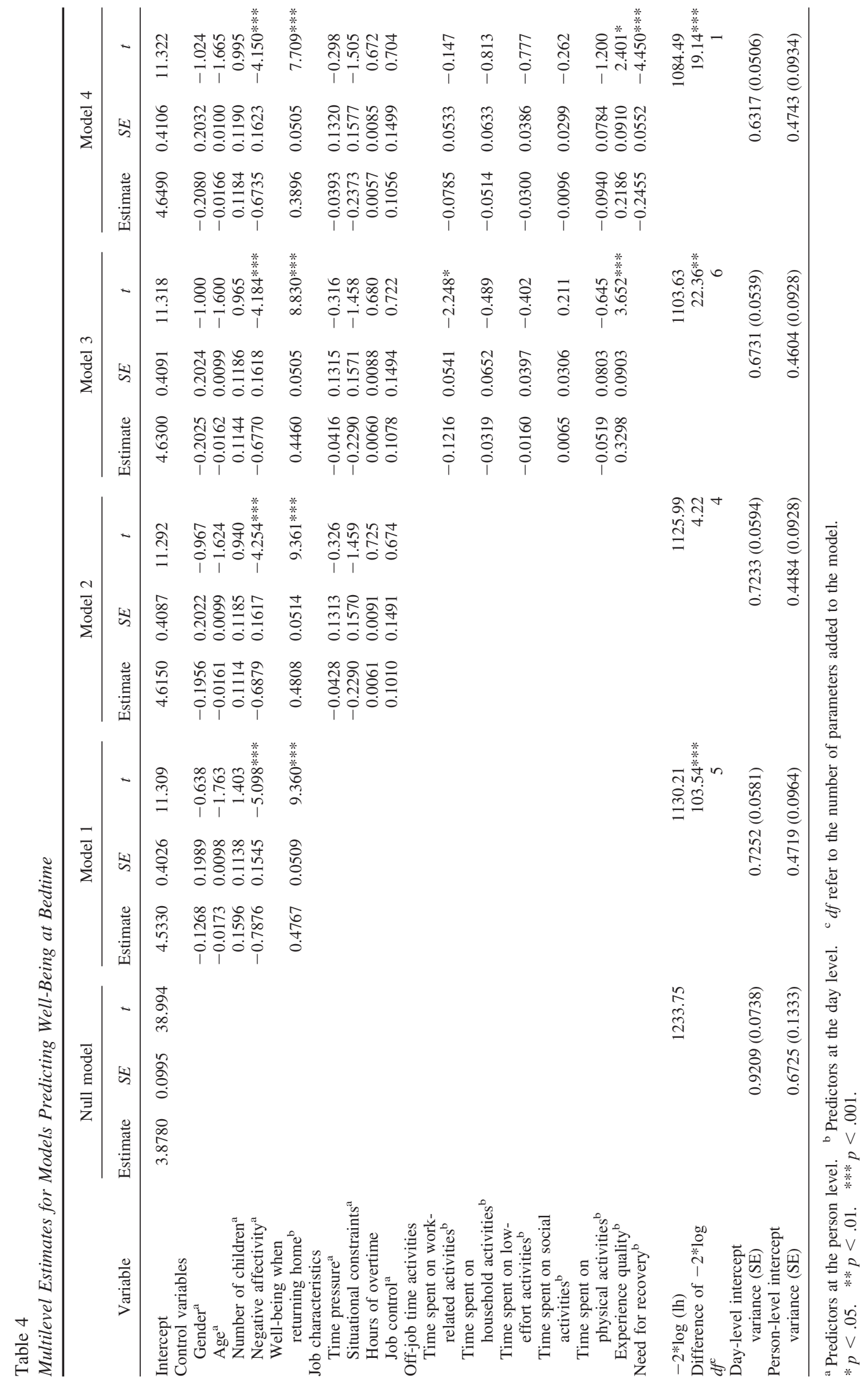


Study 1 , need for recovery was operationalized in terms of whether people had enough time available for recovery. This measure provides no insight into the intensity of the phenomenon. In Study 2 , need for recovery was operationalized in terms of the symptoms people feel when they experience a high need for recovery. Whereas in Study 1, we used well-being as a rather general outcome measure, in Study 2 we focused on fatigue as a more specific outcome measure. Also, fatigue is primarily related to the level of effort expenditure and therefore to the level of activity of the individual (Meijman, 1991). Making a change in the activity level is the way people regulate their effort expenditure and thus presumably also their recovery processes. Fatigue implies a resistance to further activity (Meijman \& Mulder, 1998), which clearly fits in well with the energetic approach to the concept of need for recovery chosen for this study. Fatigue as a specific indicator for reduced well-being should therefore be particularly sensitive to variations in need for recovery.

Our goals for Study 2 were primarily to extend our findings to a larger sample with a broader range of professions. It should be noted that we aimed not to exactly replicate the first study but rather to test the same hypotheses with different measures and with a between-person design. Because sleep is believed to be an important determinant of recovery, we examined whether more time for sleep would reduce the need for recovery. Since Study 2 comprised a substantially larger sample, it also allowed us to apply different statistical techniques (i.e., structural equation modeling [SEM]) to test our model.

\section{Study 2}

\section{Method}

In Study 2, we used data that had been collected in a cross-sectional survey among the Dutch working population. Information was collected on aspects of work and the private lives of respondents. A large number of telephone numbers were randomly selected from the Dutch telephone directory. About 4,000 people were randomly selected, called, and screened on the inclusion criterion of a minimum employment of $8 \mathrm{hr}$ per week. In this way it was possible to stratify the sample with respect to gender, age, and level of education. Those who met the inclusion criterion and agreed to cooperate received a questionnaire. In this way, 2,000 questionnaires were distributed to people's home addresses; $1,129(55.6 \%)$ were returned. For the analyses reported here, we used only a subsample of individuals who worked 36 or more hours per week.

\section{Sample}

Table 5 presents information concerning the characteristics of the group of people who responded to this survey and the subsample that was used for this study. When compared with statistics from the Netherlands' Central Bureau for Statistics (Centraal Bureau voor de Statistiek, 1999), the sample, apart from being slightly skewed toward more highly educated people, seems representative of the Dutch working population. The fact that more highly educated people are somewhat overrepresented in the sample is an artifact of the survey research methods used (Saris, 1988).

\section{Measures}

In the survey, questions were included about the respondent's work and private life domains. Table 6 presents the means, standard deviations, and zero-order correlations among the study variables.
Table 5

Characteristics of Respondents of Study 2

\begin{tabular}{|c|c|c|c|c|}
\hline \multirow[b]{2}{*}{ Characteristic } & \multicolumn{2}{|c|}{$\begin{array}{l}\text { Total sample } \\
(N=1,129)\end{array}$} & \multicolumn{2}{|c|}{$\begin{array}{l}\text { Subsample } \\
(n=704)\end{array}$} \\
\hline & Frequency & $\%$ & Frequency & $\%$ \\
\hline \multicolumn{5}{|l|}{ Gender } \\
\hline Women & 494 & 43.8 & 170 & 24.1 \\
\hline Men & 628 & 55.6 & 529 & 75.1 \\
\hline Missing & 7 & 0.6 & 5 & 0.7 \\
\hline \multicolumn{5}{|l|}{ Having children } \\
\hline None & 339 & 30.0 & 244 & 34.7 \\
\hline Yes & 695 & 61.6 & 388 & 55.1 \\
\hline Missing & 95 & 8.4 & 72 & 10.2 \\
\hline \multicolumn{5}{|l|}{ Marital status } \\
\hline Married & 658 & 58.3 & 392 & 55.7 \\
\hline Living with a partner & 192 & 17.0 & 129 & 18.3 \\
\hline Single & 271 & 24.0 & 178 & 25.3 \\
\hline Missing & 8 & 0.7 & 5 & 0.7 \\
\hline \multicolumn{5}{|l|}{ Age (years) } \\
\hline $15-24$ & 48 & 4.3 & 37 & 5.3 \\
\hline $25-34$ & 340 & 30.1 & 218 & 30.9 \\
\hline $35-44$ & 371 & 32.9 & 225 & 32.0 \\
\hline $45-54$ & 295 & 26.1 & 183 & 25.9 \\
\hline $55-64$ & 69 & 6.1 & 37 & 0.6 \\
\hline Missing & 6 & 0.5 & 4 & 5.3 \\
\hline \multicolumn{5}{|l|}{ Part time } \\
\hline$<36$ hours & 399 & 35.3 & & \\
\hline$\geq 36$ hours & 704 & 62.3 & & \\
\hline Missing & 26 & 2.3 & & \\
\hline \multicolumn{5}{|l|}{ Education } \\
\hline Basic education & 24 & 2.1 & 14 & 2.0 \\
\hline Lower professional & 224 & 19.8 & 132 & 18.8 \\
\hline Medium professional & 259 & 22.9 & 181 & 25.7 \\
\hline High school level & 109 & 9.7 & 59 & 8.4 \\
\hline Professional level & 460 & 40.7 & 282 & 40.0 \\
\hline Missing & 53 & 4.7 & 36 & 5.1 \\
\hline \multicolumn{5}{|l|}{ Industrial branch } \\
\hline Industry/agriculture & 160 & 14.2 & 137 & 19.5 \\
\hline Construction & 51 & 4.5 & 39 & 5.5 \\
\hline Trade/repairs/hotels & 129 & 11.4 & 85 & 12.1 \\
\hline Transport & 38 & 3.4 & 31 & 4.4 \\
\hline Financial services & 155 & 13.7 & 115 & 16.3 \\
\hline Care sector & 190 & 16.8 & 67 & 9.5 \\
\hline Other services & 130 & 11.5 & 68 & 9.7 \\
\hline Public sector (government) & 110 & 9.7 & 70 & 9.9 \\
\hline Education & 114 & 10.1 & 57 & 8.1 \\
\hline Missing & 52 & 4.6 & 35 & 5.0 \\
\hline
\end{tabular}

Job demands. We measured four different job demands with scales developed by Roe and Zijlstra (2000): (a) quantity of work (six items; e.g., "Is there too much work for you to do?"; Cronbach's $\alpha=.74$ ); (b) responsibility at work (five items; e.g., "Can other people be harmed or hurt when you make a mistake?"; Cronbach's $\alpha=.71$ ); (c) temporal demands (six items; e.g., "Is the time that is available for your work fixed?"and "Do you often have to work up to deadlines?"; Cronbach's $\alpha=$. 64); and (d) daily hazards at work and/or lack of support (seven items; e.g., "Are you informed in a timely manner on changes in planning?"; Cronbach's $\alpha=$. 76).

Task control. We assessed task control with a scale developed by Greenberger, Strasser, Cummings, and Dunham (1989; 7 items; e.g., "How much influence do you have on decisions such as when to take a break?"; Cronbach's $\alpha=.85$ ). Various studies have indicated good validity for this scale (Carayon \& Zijlstra, 1999; McLaney \& Hurrell, 1988).

Overtime. We computed overtime hours by subtracting contract work hours from actual work hours. 
Table 6

Means, Standard Deviations, and Zero-Order Correlations Among Study 2 Variables

\begin{tabular}{|c|c|c|c|c|c|c|c|c|c|c|c|c|c|c|c|c|}
\hline Variable & $M$ & $S D$ & 1 & 2 & 3 & 4 & 5 & 6 & 7 & 8 & 9 & 10 & 11 & 12 & 13 & 14 \\
\hline 1. Quantity of work & 3.42 & 0.69 & - & & & & & & & & & & & & & \\
\hline 2. Responsibility at work & 2.84 & 0.84 & .38 & - & & & & & & & & & & & & \\
\hline 3. Temporal demands & 3.03 & 0.67 & .45 & .40 & - & & & & & & & & & & & \\
\hline 4. Hazards & 2.35 & 0.65 & .15 & -.10 & .01 & - & & & & & & & & & & \\
\hline 5. Task control & 3.40 & 0.68 & -.05 & .17 & -.12 & -.26 & - & & & & & & & & & \\
\hline 6. Fatigue & 3.00 & 1.44 & .20 & -.04 & .03 & .30 & -.24 & - & & & & & & & & \\
\hline 7. Need for recovery & 3.05 & 1.51 & .34 & .10 & .18 & .35 & -.28 & .58 & - & & & & & & & \\
\hline 8. Overtime & 6.02 & 9.25 & .30 & .28 & .22 & -.00 & .04 & .06 & .17 & - & & & & & & \\
\hline 9. Household activities & 10.74 & 8.17 & -.02 & -.04 & .02 & -.00 & -.07 & .02 & .01 & -.06 & - & & & & & \\
\hline 10. Care activities & 1.81 & 5.41 & -.01 & .13 & .08 & .03 & .07 & .01 & -.04 & .00 & .14 & - & & & & \\
\hline 11. Sleep & 7.09 & 2.71 & -.03 & -.01 & -.02 & -.04 & .03 & -.01 & -.03 & -.09 & .25 & -.04 & - & & & \\
\hline 12. Effort investment & 22.23 & 23.75 & .10 & .04 & .03 & .08 & -.11 & .16 & .18 & .04 & .05 & .08 & -.04 & - & & \\
\hline 13. Leisure activities & 2.49 & 0.90 & -.01 & -.02 & -.01 & -.05 & -.05 & -.13 & -.11 & -.09 & -.00 & -.07 & .01 & -.07 & - & \\
\hline 14. Common method factor & 11.59 & 6.04 & .03 & .06 & .03 & .03 & .05 & .00 & -.01 & .03 & .06 & .06 & -.04 & .03 & .02 & - \\
\hline
\end{tabular}

Note. $\quad N=704$. All correlations $\geq .10$ are significant at $p<.01$.

Effort investment. We measured effort investment with the Rating Scale Mental Effort (RSME; Zijlstra, 1993). The RSME is a onedimensional rating scale and has proven to be reliable, valid, sensitive to changes in task demands, and easily applicable in all kind of situations (Verwey \& Veltman, 1996; Zijlstra, 1993). Respondents were asked to rate their average effort investment on two occasions: in the morning when they started their working day and at the end of their working day.

Time budget data. Respondents provided time budget data about work and nonwork activities. Specifically, they were asked to indicate how much time they actually spent per week on various categories of activities. The classes of activities listed were as follows: work activities (excluding time for commuting), household activities (cleaning, shopping, maintenance), care taking (feeding, washing, playing, and transporting children), and leisure activities (hobbies, sports, cultural activities). Respondents were also requested to indicate their sleeping patterns in terms of average number of hours of sleep on weekdays and on free days (weekends).

Need for recovery. Need for recovery was measured with a scale developed by Van Veldhoven and Meijman (1994) and tested by Sluiter et al. (1999). This scale focuses on the symptoms of having had an intensive working day (five items; e.g., "When I get home after work, I want to be left in peace for a while" and "I have difficulties in showing interest in other people immediately after I get home from work"; Cronbach's $\alpha=$ $.85)$.

Fatigue. We measured fatigue as an indicator of poor well-being and of level of activity. Specifically, we used the General Fatigue scale from the Checklist of Individual Strength (CIS-20; Vercoulen et al., 1994) and asked our respondents to refer to the last 2 weeks ( 7 items; e.g., "I feel myself being in a physically poor condition," "I feel tired," and "I feel weak"; Cronbach's $\alpha=.92$ ).

Demographic variables. We assessed the following demographic data: gender, age, marital status, number of children, and level of education.

\section{Analyses}

In studies relating to job demands, workload, and outcomes of work, such as fatigue, the results tend to be influenced by the number of hours people work per week. To control for this part-time factor, we included only respondents who worked full time (more than $35 \mathrm{hr}$ per week; $N=$ 704) in the analyses (see Table 5).

The measures used in our analyses were part of a large survey aimed at taking an inventory of relevant issues in respondents' working lives, such as work pressure, fatigue, health, and work-family balance. Surveys that are based on self-report methods and that collect data at one moment in time are generally believed to have serious methodological weaknesses, because the results may be susceptible to common method variance. To estimate the common method variance in this study, we computed a common method factor by following a procedure, successfully applied by De Vries, Roe, \& Taillieu (1998, 2002), that depends on the availability of other same-source data (Crampton \& Wagner, 1994). A number of items were randomly selected from the scales that were theoretically unrelated to this study and were factor analyzed (principal components analysis). The last factor that had an eigenvalue larger than 1.0, and that could not be interpreted in terms of one of the study variables, was believed to reflect the common method variance in this study. This factor contained three items with factor loadings higher than .45 (e.g., "To what extent do you get feedback about the quality of your work from the work itself?") and explained $7.8 \%$ of the variance. This factor was used as a scale and was included in further analyses in order to correct for common method variance. Table 6 clearly shows that this newly created common method factor did not correlate significantly with any of the study variables. Correlations were low, and never higher than .10, suggesting that the variance in the results that can be attributed to this common method variance can never be more than $1 \%$. Although this correlation was marginal, in the analyses the common method factor was included as a control variable.

Table 6 shows a strong positive correlation between fatigue and need for recovery. Although both concepts are conceptually related and a high positive correlation can be expected between these concepts, a check on whether these two scales are sufficiently distinct from each other is certainly justified. To this end, the items from the Need for Recovery scale and the General Fatigue scale were subjected to a principal components analysis with varimax rotation. This analysis resulted in two factors with eigenvalues greater than 1 , explaining $66 \%$ of the variance. The first factor, explaining $52 \%$ of the variance, had only loadings of items from the General Fatigue scale. None of the Need for Recovery items had their highest loadings on this factor, and they were never higher than .35 . The second factor, explaining an additional $14 \%$ of the variance, consisted only of items belonging to the Need for Recovery scale. This result suggests that both dimensions are sufficiently distinct from each other to justify using need for recovery and fatigue as two distinct measures in further analyses.

\section{Results}

Table 6 shows that the job demands scales correlated moderately with each other. Fatigue was positively correlated with the 
quantity of work, and with job hazards and/or lack of support, whereas it was not correlated with responsibility and temporal demands. Need for recovery was positively associated with all of the job demands. Overtime was associated with need for recovery but not with fatigue. This means that fatigue and need for recovery are each related to different aspects of work.

Time for household activities was not significantly related to job demands. Time for care activities was significantly related to the job demand of responsibility. This finding suggests that job demands and demands from the private life domain are relatively independent from each other.

\section{Test of Hypotheses}

To Test Hypotheses 1, 2, 4, and 5, we conducted a series of hierarchical regression analyses. In the first analysis, need for recovery was the dependent variable, with four blocks of predictor variables. The first block (Model 1) contained the common method variable and demographic parameters. The second block (Model 2) contained the variables related to job demands (testing Hypothesis 1) and task control (testing Hypothesis 2). The third block (Model 3) included the domestic demands (testing Hypothesis 4), and the fourth block of predictors (Model 4) consisted of time for leisure (Hypothesis 5) and time for sleep (Hypothesis 5a). The last block (Model 5) consisted of the interaction terms between job demands and off-job activities. The results are presented in Table 7. Only the last four of the five models were statistically significant.

Model 2 explained 25\% of the variance. The job-related aspects had a significant contribution in predicting need for recovery. In particular, people's assessment of their amount of work, the extent to which they experienced daily hazards and/or lack of support, the amount of effort they had to invest in their work, and the amount of overtime they put in were positively related to need for recovery. These four variables refer to how hard people have to work. Daily hazards and/or lack of support had a particularly high beta weight. To overcome daily hazards, people have to work a bit harder or have to be extra motivated. These findings support Hypothesis 1, that job demands are positively related to need for recovery. Task control had a significant but negative contribution, suggesting that control can be used to counteract potential negative effects on health and well-being. This finding supports Hypothesis 2. Task control implies, for instance, that people have the opportunity to determine their own work pace or to schedule their own breaks.

Model 3, which included the domestic demands (time for household and time for care), did not add to the prediction of need for recovery. This means that the amount of time people spent on household and care-taking activities did not contribute to the prediction of need for recovery. This result makes clear that the domestic demands did not explain any variance over and above that explained by the job demands in predicting need for recovery. Thus, Hypothesis 4 was not supported (Hypothesis 3 was not tested in Study 2).

On the whole, Model 4, which included time for leisure activities and time for sleep, did not show a significant increase in explained variance. However, the amount of time spent on leisure activities was a significant negative predictor of need for recovery, which suggests that the amount of time spent on leisure activities helps to reduce need for recovery. These results support Hypoth- esis 5. Amount of sleep was not significantly related to need for recovery, and thus Hypothesis 5a was not supported in this model. The fifth block did not contain any significant interactions. This finding suggests that a model with simple additive effects is more plausible than a model with interaction effects. Hypothesis 6 was not tested in Study 2, and a positive correlation was found between fatigue (as a specific and short-term indicator of well-being) and need for recovery, which supports Hypothesis 7.

To test Hypothesis 8, predicting that need for recovery mediates the effect of demands on level of well-being, we tested the model presented in Figure 1 using structural equation modeling. The results are presented in Figure 2. The model appears to fit the data rather well: The root-mean-square error of approximation (RMSEA) for the mediation model was $0.051 ; \chi^{2}(35)=73.73$, $p=.0001$; the goodness of fit index (GFI) was .97; the adjusted GFI (AGFI) was .94; and the normed fit index (NFI) was .90. A model that assumed that the effect of demands is not mediated by need for recovery but that demands have a direct effect on wellbeing appeared to fit the data less well: RMSEA $=0.092$; $\chi^{2}(35)=163.12, p<.0000 ; \mathrm{GFI}=.94 ; \mathrm{NFI}=.80$. An examination of the modification indexes revealed that the overall fit of the model could not be substantially improved by freeing any of the remaining paths.

Figure 2 shows that job demands are positively related to need for recovery, indicating that a higher level of demands is associated with a higher need for recovery. Job control is negatively related to need for recovery. Domestic demands appear to have virtually no effect on need for recovery, whereas leisure activities again are negatively related to need for recovery. In this model, amount of sleep appears to be positively related to need for recovery.

\section{Discussion}

Study 2, like Study 1, showed that high levels of job demands are positively related to need for recovery (Hypothesis 1). In addition, task control was negatively related to need for recovery. This was predicted in Hypothesis 2 and is in line with the literature on task control (Karasek \& Theorell, 1990; Sauter, Hurrell, \& Cooper, 1989). The results also showed that there the various job demands have differential effects on need for recovery. In particular, the job demands of quantity of work and daily hazards and/or lack of support contributed significantly to the prediction of need for recovery. It should be noted that experiencing and overcoming daily hazards and/or lack of support had by far the highest beta weight. Also, effort investment and amount of overtime were positively related to need for recovery. This clearly suggests that need for recovery is related to a high activity level. In particular, overcoming hazards and dealing with lack of support can be quite strenuous and therefore cost considerable effort. This finding is in line with the results reported by Meijman et al. (1992), who demonstrated that intensity of work is an important predictor of need for recovery.

Responsibility on the job was related neither to need for recovery nor to fatigue. Apparently, responsibility is not generally perceived as a real burden. This can be explained by the fact that people in high-responsibility jobs are often found in the higher level and managerial jobs. Apart from the fact that high responsibility usually coincides with high levels of task control, people in 
Table 7

Hierarchical Regression Analysis Predicting Need for Recovery

\begin{tabular}{|c|c|c|c|c|c|c|c|c|c|c|}
\hline \multirow[b]{2}{*}{ Variable } & \multicolumn{2}{|c|}{ Model 1} & \multicolumn{2}{|c|}{ Model 2} & \multicolumn{2}{|c|}{ Model 3} & \multicolumn{2}{|c|}{ Model 4} & \multicolumn{2}{|c|}{ Model 5} \\
\hline & Beta & $t$ & Beta & $t$ & Beta & $t$ & Beta & $t$ & Beta & $t$ \\
\hline \multicolumn{11}{|l|}{ Control variables } \\
\hline Common method factor & -.02 & -.30 & -.02 & -.45 & -.02 & -.42 & -.02 & -.39 & -.02 & -.32 \\
\hline Age & .12 & 1.80 & .11 & 1.89 & .11 & 1.79 & .11 & 1.77 & .13 & $1.98^{*}$ \\
\hline $\operatorname{Sex}$ & .07 & 1.23 & .10 & 1.84 & .10 & 1.86 & .10 & 1.85 & .10 & 1.71 \\
\hline Level of education & .01 & .23 & -.04 & -.81 & -.04 & -.78 & -.02 & -.40 & -.01 & -.12 \\
\hline Number of children & .04 & .56 & .01 & .23 & .03 & .42 & .01 & .15 & -.00 & -.01 \\
\hline \multicolumn{11}{|l|}{ Job characteristics } \\
\hline Quantity of work & & & .14 & $2.36 *$ & .14 & $2.32 *$ & .14 & $2.32 *$ & .19 & $2.49^{*}$ \\
\hline Responsibility at work & & & -.04 & -.67 & -.04 & -.63 & -.04 & -.67 & -.02 & -.29 \\
\hline Temporal demands & & & .09 & 1.48 & .09 & 1.53 & .09 & 1.58 & .05 & .63 \\
\hline Hazards & & & .26 & $5.08 * *$ & .26 & $5.07 * *$ & .25 & $4.84 * *$ & .19 & $2.76^{* * *}$ \\
\hline Task control & & & -.20 & $-3.79 * *$ & -.20 & $-3.75 * *$ & -.21 & $-3.93 * *$ & -.18 & $-3.42 * *$ \\
\hline Overtime & & & .12 & $2.41 *$ & .13 & $2.35^{* * *}$ & .14 & $2.35^{*}$ & .14 & $2.54 *$ \\
\hline Effort investment & & & .19 & $3.88 * *$ & .20 & $3.92 * *$ & .19 & $3.72 * *$ & .21 & $3.53 * *$ \\
\hline \multicolumn{11}{|l|}{ Off-job activities } \\
\hline Household activities & & & & & -.03 & -.53 & -.02 & -.44 & -.05 & -.76 \\
\hline Care activities & & & & & -.03 & -.53 & -.03 & -.54 & .05 & .45 \\
\hline Leisure activities & & & & & & & -.10 & $-2.07 *$ & -.12 & $-2.29 *$ \\
\hline Sleep & & & & & & & -.01 & -.15 & .13 & .79 \\
\hline \multicolumn{11}{|l|}{ Interaction effects } \\
\hline Quantity $\times$ Leisure & & & & & & & & & -.10 & -1.65 \\
\hline Quantity $\times$ Sleep & & & & & & & & & .30 & 1.70 \\
\hline Quantity $\times$ Household & & & & & & & & & -.06 & -.73 \\
\hline Quantity $\times$ Care & & & & & & & & & .11 & 1.42 \\
\hline Responsibility $\times$ Leisure & & & & & & & & & .02 & .36 \\
\hline Responsibility $\times$ Sleep & & & & & & & & & -.05 & -.55 \\
\hline Responsibility $\times$ Household & & & & & & & & & .04 & .56 \\
\hline Responsibility $\times$ Care & & & & & & & & & .05 & .26 \\
\hline Temporal $\times$ Leisure & & & & & & & & & -.05 & -.74 \\
\hline Temporal $\times$ Sleep & & & & & & & & & -.01 & -.08 \\
\hline Temporal $\times$ Household & & & & & & & & & -.02 & -.26 \\
\hline Temporal $\times$ Care & & & & & & & & & -.24 & -1.79 \\
\hline Hazards $\times$ Leisure & & & & & & & & & -.04 & -.68 \\
\hline Hazards $\times$ Sleep & & & & & & & & & -.09 & -1.52 \\
\hline Hazards $\times$ Household & & & & & & & & & .01 & .21 \\
\hline Hazards $\times$ Care & & & & & & & & & .03 & .26 \\
\hline Overtime $\times$ Leisure & & & & & & & & & .00 & .05 \\
\hline Overtime $\times$ Sleep & & & & & & & & & -.13 & -.96 \\
\hline Overtime $\times$ Household & & & & & & & & & -.07 & -1.08 \\
\hline Overtime $\times$ Care & & & & & & & & & -.07 & -.88 \\
\hline Effort $\times$ Leisure & & & & & & & & & .07 & 1.35 \\
\hline Effort $\times$ Sleep & & & & & & & & & .01 & .05 \\
\hline Effort $\times$ Household & & & & & & & & & .04 & .62 \\
\hline Effort $\times$ Care & & & & & & & & & -.05 & -.31 \\
\hline Adjusted $R^{2}$ & \multicolumn{2}{|c|}{.01} & \multicolumn{2}{|c|}{.25} & \multicolumn{2}{|c|}{.25} & \multicolumn{2}{|c|}{.26} & \multicolumn{2}{|c|}{.27} \\
\hline$F$ & \multicolumn{2}{|c|}{1.35} & \multicolumn{2}{|c|}{$10.25 * *$} & \multicolumn{2}{|c|}{$8.80 * *$} & \multicolumn{2}{|c|}{$8.02 * *$} & & $3 * *$ \\
\hline$\Delta R^{2}$ & & 2 & & & & & & & & \\
\hline$F\left(\Delta R^{2}\right)$ & & & & $0 * *$ & & & & & & \\
\hline
\end{tabular}

$* p<.05 . \quad * * p<.01$.

higher level jobs will usually also enjoy their work more and find their jobs more rewarding than will people in lower level jobs (Carlopio \& Gardner, 1995; Coyle-Shapiro \& Kessler, 2002).

Although Hypothesis 3 was not explicitly tested in Study 2, the positive relation of overtime (or rather "extra" time) with need for recovery suggests that the more time is spent on work and workrelated activities, the higher the need for recovery. This finding might be seen as indicative of support for Hypothesis 3 in this study.
Furthermore, the amount of time spent on household and on care activities was not related to need for recovery (as in Study 1). This clearly contradicts Hypothesis 4. Apparently, the amount of time that needs to be spent on household and care activities is not an indication of the weight of the demands placed on the individual.

The amount of time people had available for leisure was negatively related to their need for recovery. Although in Study 2 the various leisure activities were not differentiated, the results suggest that Hypothesis 5 was confirmed. Unexpectedly, amount of time 


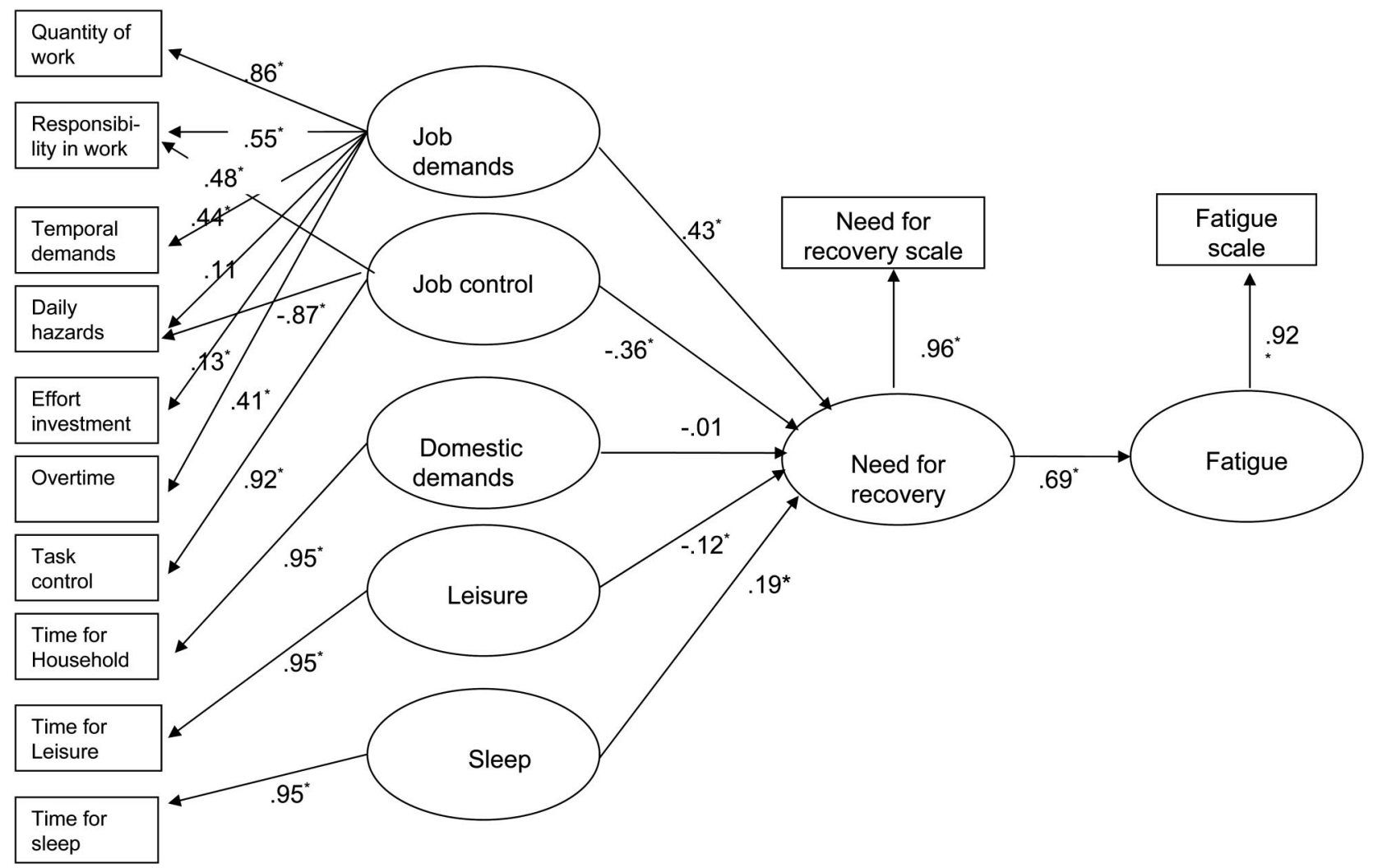

Figure 2. Standardized path coefficients for structural equation model. $\chi^{2}(35)=73.73, p=.0001$; root-meansquare error of approximation $=0.051$; goodness of fit index $=.97$; adjusted goodness of fit index $=.94$; normed fit index $=.90$.

for sleep was not related to need for recovery in the regression model. To explain this finding, we may have to look at results reported by Åkerstedt et al. (2002), who suggested that sleep disturbances are positively related to high work demands. In particular, impaired awakening (i.e., not feeling well rested after disturbed sleep) appeared to be positively related to a high level of work demands and high effort at work. These findings suggest that, in terms of recovery, the quality of the sleep (i.e., absence of disturbances) seems to be more important than the length of the sleep period per se. People with disturbed sleep do not feel well rested and have a higher need for recovery when getting up. The positive relation between amount of sleep and need for recovery in the structural equation model contrasts with the hypothesis, which predicted a negative relation. Our hypothesis (and other studies) focused on the amount of sleep people had in the night preceding the working day. Lack of sleep would then indicate a lack of recovery and consequently a higher need for recovery. However, a recent survey on sleep behavior in the United Kingdom (Groeger, Zijlstra, \& Dijk, 2004) showed that working people do not show much variation in their sleeping pattern on work days; the most frequent time to go to bed is around 11:30 p.m. But for most working people, the alarm is set for 7:00 a.m. This means that the variation can primarily be found in the times at which people go to bed. When people have a high need for recovery, they go to bed early, which thus suggests that need for recovery may determine the amount of sleep, rather than the other way around. However, how the process of sleep contributes to recovery will have to be a topic of future research.

The structural equation model confirms the conceptual model presented in Figure 1. Both job demands and some off-job activities are related to need for recovery, need for recovery is strongly related to well-being, and the effects of job demands and off-job activities on well-being are mediated by need for recovery.

This second study also has some limitations. First, all results were obtained in a cross-sectional survey, and therefore no causal interpretations are allowed. People with a high need for recovery might perceive job demands as more taxing than might people with a low need for recovery. However, Study 1, which had a withinsubject design, partly rules out this explanation. Nevertheless, a longitudinal study would be ideal because it would allow causal interpretations. Second, surveys normally are criticized for being subject to common method variance (Crampton \& Wagner, 1994). However, to rule out such a common method variance interpretation, we computed a common method factor and included this factor as a control variable in the analyses. Therefore, we believe that our results are not biased by common method variance.

Another limitation was that participants were asked to indicate the average amount of time they usually spent on various activities. This meant that participants had to respond in hindsight, and this fact might have triggered various types of biases, such as social desirability, inaccuracy in remembering, or errors in assessing the length of time. However, we do believe that, 
again, in combination with the Study 1 results, in which daily survey information was obtained, the results of Study 2 present converging evidence.

\section{General Discussion}

The two studies provided support for most of our hypotheses. Job demands and job control were related to need for recovery, fatigue, and well-being. The effects of job demands and job control on fatigue and well-being were mediated by need for recovery. In particular, situational constraints (Study 1) and daily hazards and/or lack of support (Study 2) were associated with a high need for recovery. These job demands refer to unfavorable working conditions with obstacles and hindrances that are particularly bothersome and require specific additional effort to be overcome. Effort investment and work quantity were also important predictors of need for recovery in Study 2.

Other job demands, such as temporal demands (Study 2), uncertainty (Study 1), and responsibility (Study 2), were not related to need for recovery. These job demands are usually perceived as important potential stressors. However, one might argue that although these demands are important, they do not necessarily require extra activities in order to cope with them. This means that no specific extra effort is required, whereas the demands that are indeed related to need for recovery refer directly to the investment of (mental) effort. This is an indication that need for recovery is associated with work that places high demands on people's physical and psychological resources, be it through high hazards and situational constraints, extended working days, or a high workload (also Meijman et al., 1992; Rissler \& Elgerot, 1978; Sluiter et al., 1999). In Study 1, time pressure was no significant predictor of need for recovery. This finding might be due to the specific study setting. In health care institutions, employees might regard time pressure as inevitable because of arising emergency situations. Therefore, they will perceive situational constraints as more stressful and annoying, resulting in an elevated level of need for recovery.

Furthermore, both studies indicated that control over the task was negatively related to need for recovery, which suggests that having the discretion over when to take a break and what strategy to follow does reduce need for recovery. Thus, one might conclude that need for recovery is primarily related to people's ability to regulate their effort investment (Zijlstra, 1996). The regulation of effort depends on opportunities to do so. For example, there should be time available, and circumstances (other activities) should allow it. Empirical studies have already indicated that the secretion of catecholamines is elevated during work time, when people are exposed to high work demands (e.g., Kuiper et al., 1998). This level of secretion should decrease during off-work periods, when people are expected to recover from the strains of the work day. However, sustained activation of the sympathoadrenal system during the hours after work means that the system cannot unwind and that recovery cannot take place. This phenomenon of incomplete unwinding-described as "spillover" in the literature-may lead to mental and physical health problems (Dienstbier, 1989; Knardahl \& Ursin, 1985). Need for recovery may be seen as a psychological early warning indicator that can help people to regulate their effort investment, and therefore it may eventually help to prevent health problems.
Study 1 showed that apart from job demands, well-being when coming home is a particularly important predictor of well-being when going to bed. This finding is in line with results reported by Kuiper et al. (1998), who demonstrated that the speed of unwinding after work depends on the level of work demands, personal characteristics, and the state of general well-being. The level of well-being immediately after work is evidently substantially correlated with experiences at work. This finding suggests that people's need for recovery and their speed of recovery are largely determined by work demands.

The results of both studies also indicated that the various types of off-job activities contributed to the explanation of need for recovery in the predicted way. Time spent on leisure was negatively related to need for recovery in Study 2, indicating that leisure activities stimulate recovery. However, as Study 1 demonstrated, not all leisure activities contributed to need for recovery. Time spent on low-effort activities (i.e., passive types of activities) was not related to need for recovery. Apparently, it is better to be actively engaged in activities (social activities, physical activities) because this may help to switch off from work. Experience quality, assessed in Study 1, was strongly related to need for recovery, which suggests that it is not only the type and duration of an activity that contribute to recovery and well-being but also its experience quality.

In both studies, time spent on household and child-care activities was not related to need for recovery, whereas in both studies time spent on work was significantly related to need for recovery (time spent on work-related activities in Study 1, and overtime in Study 2 , respectively). This pattern of findings suggests that one cannot simply add up work-related and other domestic demands in order to assess the total impact of those demands. Apparently there are qualitative differences between these various demands. In fact, one might also claim that spending time on household and child care may have a beneficial effect on recovery, because it may help to switch off from job-related demands. In particular, when work has been intensive and demanding, individuals may find relief in doing some household activities. This line of reasoning is supported by findings by Waldron, Weiss, and Hughes (1998), who suggested that married individuals and individuals with children evaluate their private life situation as more satisfactory than do singles and married individuals without children. Married individuals appeared to be healthier, had a higher level of well-being, and lived longer than singles (Cordes \& Dougherty, 1993). Looking after and caring for others can be highly rewarding and may therefore be beneficial for recovery.

We conducted our studies in two different countries and used different but complementary study designs and measures. Study 1 focused on a specific professional group and explored the withinperson variance, whereas Study 2 was based on a cross-sectional nationwide survey and focused on between-person variance. Both studies do have their own specific limitations and strengths, but when the studies are combined, the weaknesses of one study can be compensated for by the strengths of the other, and vice versa. In both studies, need for recovery mediated the relationship among job demands, job control, and off-job activities, on the one hand, and individual strain, on the other hand, both between and within persons. Need for recovery appears to be an important variable that refers to the underlying mechanism of effort regulation. Like a marathon runner, a worker has to regulate his or her effort expen- 
diture throughout the day in order to complete the working day. Whether individuals are successful in regulating their effort expenditure explains why some individuals experience fatigue and others do not (Zijlstra, 1996). The difference in the conceptualizations of need for recovery in our two studies indicates that both the time available for recovery (Study 1) and the level of the symptoms (Study 2) are important. The perception of having neither time nor opportunity to recover might be an immediate precursor of specific need-for-recovery symptoms. Alternatively, it might also be that individuals who experience such symptoms attribute these symptoms to a lack of time and opportunities to recover. Future studies should examine this process in more detail.

Our core outcome measures were a rather general well-being measure in Study 1 and a much more specific activity-related indicator of strain, fatigue, in Study 2. Results from the two studies together suggest that need for recovery is reflected not only in increased fatigue, which is a specific outcome conceptually closely linked to recovery, but also in a more general experience of poorwell-being. Therefore, one may speculate that the effects of recovery processes are not limited to the functional systems affected by previous stressors but generalize to other aspects of a person's functioning.

\section{Limitations}

Our studies have some limitations. First, both studies relied on self-report data. In Study 2, we explicitly addressed this shortcoming and controlled for a common method factor in the analyses. This procedure suggests that our study findings cannot be accounted for by a common method factor. In addition, we used two different data collection methods in the two studies (diary and survey). Thus, our findings cannot be accounted for by one specific data collection method. Nevertheless, we recommend including more objective indicators in future studies. One might consider physiological strain measures or spouse ratings of off-job activities. There was no opportunity to control for negative affectivity in Study 2. However, because controlling for negative affectivity in Study 1 did not affect the study findings, we assume that it is not a major problem in Study 2 either. In addition, one might argue that respondents' estimation of time spent on specific activities might be influenced by the characteristics of the activities these respondents engaged in (Michon, 1975; Schiffman \& GreistBousquet, 1992). To overcome this shortcoming, future studies might use experience- and time-sampling methods. It would be useful to use small handheld computers that might prompt respondents at various moments to indicate the type and duration of activities they are engaged in.

\section{Implications for Future Research and Practice}

Our studies have implications for future research. We examined short-term changes in well-being in Study 1 and relied on a cross-sectional design in Study 2. Future studies should examine the effects of job characteristics and off-job experiences on need for recovery and the consequences of need for recovery over longer periods of time; they should also look at recovery activities and need for recovery in more detail. In our studies, we concep- tualized need for recovery as an outcome of job characteristics and off-job activities. It would be an option for future research to assess need for recovery as an immediate reaction to job characteristics that in turn affects the choice and experience of specific recovery activities. Thus, after-work need for recovery could be conceptualized as a mediator between job demands and off-job activities. Off-job activities would then be the mediator between job characteristics and after-work need for recovery, on the one hand, and bedtime need for recovery, on the other hand. The test of such a model would require an even more fine-grained data collection procedure than the one used in Study 1. Moreover, future research should address factors that help individuals initiate and uphold those off-job activities that are helpful in reducing need for recovery and in improving well-being. In addition, it would be interesting to examine the relationship between opportunities for recovery and actual recovery activities. Although it is plausible that opportunities for recovery and actual pursuit of recovery activities are positively related, there might be situations in which individuals do not perform the most successful recovery activities even when time and opportunities for recovery are available (Sonnentag \& Jelden, 2005).

Our studies offer some practical implications. We suggest regarding a high subjective need for recovery as an early warning indicator for prolonged fatigue and reduced well-being. Paying attention to this indicator and spending time on recovery may help in preventing fatigue and reduced work performance. Moreover, our studies suggest that need for recovery may decrease when workload is reduced and job control is enhanced. Implementing company policies that prevent extended working days and promote active leisure activities after work may help individuals to disengage from the daily strains of work.

Our two studies stress the importance of actual recovery from daily strains and provide empirical evidence for the model presented in Figure 1. Both job characteristics and off-job activities are related to need for recovery, and need for recovery mediates the effects of job demands and low job control on poor well-being and fatigue. Thus, recovery might be one of the crucial processes that link reversible and irreversible health complaints (Meijman \& Mulder, 1998). Lack of adequate recovery might lead to cumulative fatigue and might ultimately cause serious health complaints (Knardahl \& Ursin, 1985; Rissler \& Elgerot, 1978). Need for recovery can be seen as an early predictor of reduced well-being and - as the results of our studies suggest — as a sensitive indicator too.

\section{References}

Åkerstedt, T., Knutsson, A., Westerholm, P., Theorell, T., Alfredson, L., \& Kecklund, G. (2002). Sleep disturbances, work stress and work hours. A cross-sectional study. Journal of Psychosomatic Research, 53, 741-748.

Apenburg, E. (1986). Befindlichkeitsbeschreibung als Methode der Beanspruchungs-messung [Description of well-being as a method for measuring strain]. Psychologie und Praxis, 30, 3-14.

Baldwin, P. J. (1999). Nursing. In J. Firth-Cozens \& R. L. Payne (Eds.), Stress in health professionals (pp. 93-104). Chichester, England: Wiley.

Baron, R. M., \& Kenny, D. A. (1986). The moderator-mediator variable distinction in social psychological research: Conceptual, strategic and statistical considerations. Journal of Personality and Social Psychology, 51, 1173-1182. 
Bekker, M. H. J., de Jong, P. F., Zijlstra, F. R. H., \& van Landeghem, B. A. J. (2000). Combining care and work: Health, mood states, cognitive functioning and stress in male and female academics. International Journal for Behavioral Medicine, 7, 28-43.

Bryk, A. S., \& Raudenbush, S. W. (1992). Hierarchical linear models: Application and data analysis methods. Newbury Park, CA: Sage.

Burke, M. J., Brief, A. P., \& George, J. M. (1993). The role of negative affectivity in understanding relations between self-reports of stressors and strains: A comment on the applied psychology literature. Journal of Applied Psychology, 78, 402-412.

Carayon, P., \& Zijlstra, F. R. H. (1999). Relationship between job control, work pressure and strain: Studies in the USA and the Netherlands. Work \& Stress, 13, 32-48.

Carlopio, J., \& Gardner, D. (1995). Perceptions of work and workplace: Mediators of the relationship between job level and employee reactions. Journal of Occupational and Organizational Psychology, 68, 321-326. Centraal Bureau voor de Statistiek. (1999). Leefsituatie van de Nederlandse Bevolking 1997. Deel 1: Gezondheid en Kwaliteit van Arbeid [Social situation of the Dutch population 1997. Part 1: Health and quality of work]. Heerlen, the Netherlands: Author.

Cordes, C. L., \& Dougherty, T. W. (1993). A review and an integration of research on job burnout. Academy of Management Review, 18, 621-656.

Coyle-Shapiro, J. A. M., \& Kessler, I. (2002). Exploring reciprocity through the lens of the psychological contract: Employee and employer perspectives. European Journal of Work and Organizational Psychology, 11, 69-86.

Craig, A., \& Cooper, R. E. (1992). Symptoms of acute and chronic fatigue. In A. P. Smith \& D. M. Jones (Eds.), Handbook of human performance (Vol. 3, pp. 289-339). London: Academic Press.

Crampton, S. M., \& Wagner, J. A. (1994). Percept-percept inflation in micro-organizational research: An investigation of prevalence and effect. Journal of Applied Psychology, 79, 67-76.

de Croon, E. M., Sluiter, J. K., Blonk, R. W. B., Broersen, J. P. J., \& Frings-Dresen, M. H. W. (2004). Stressful work, psychological job strain, and turnover: A 2-year prospective cohort study of truck drivers. Journal of Applied Psychology, 89, 442-454.

De Vries, R. E., Roe, R. A., \& Taillieu, T. C. B. (1998). Need for supervision: Its impact on leadership effectiveness. Journal of Applied Behavioral Science, 34, 486-501.

De Vries, R. E., Roe, R. A., \& Taillieu, T. C. B. (2002). Need for leadership as a moderator of the relationships between leadership and individual outcomes. Leadership Quarterly, 13, 121-137.

Dienstbier, R. A. (1989). Arousal and physiological toughness: Implications for mental and physical health. Psychological Review, 96, 84-100.

Etzion, D., Eden, D., \& Lapidot, Y. (1998). Relief from job stressors and burnout: Reserve service as a respite. Journal of Applied Psychology, 83, 577-585.

Firth-Cozens, J. (1999). The psychological problems of doctors. In J. Firth-Cozens \& R. L. Payne (Eds.), Stress in health professionals (pp. 79-91). Chichester, England: Wiley.

Frankenhauser, M. (1981). Coping with stress at work. International Journal of Health Services, 11, 491-510.

Frone, M. R., Russell, M., \& Cooper, M. L. (1991). Relationship of work and family stressors to psychological distress: The independent moderating influence of social support, mastery, active coping, and selffocused attention. Journal of Social Behavior and Personality, 6, $227-$ 250

Frone, M. R., Russell, M., \& Cooper, M. L. (1997). Relation of workfamily conflict to health outcomes: A four-year longitudinal study of employed parents. Journal of Occupational and Organizational Psychology, 70, 325-335.

Geurts, S. A. E., Kompier, M. A. J., Roxburgh, S., \& Houtman, I. L. D. (2003). Does work-home interference mediate the relationship between workload and well-being? A multi-sample analysis. Journal of Vocational Behavior, 63, 532-559.

Grandey, A. A., \& Cropanzano, R. (1999). The conservation of resources model applied to work-family conflict and strain. Journal of Vocational Behavior, 54, 350-370.

Greenberger, D. B., Strasser, S., Cummings, L. L., \& Dunham, R. B (1989). The impact of personal control on performance and satisfaction. Organizational Behavior and Human Decision Processes, 43, 29-51.

Groeger, J. A., Zijlstra, F. R. H., \& Dijk., D.-J. (2004). Sleep quantity, sleep difficulties and their perceived consequences in a representative sample of some 2000 British adults. Journal of Sleep Research, 13, 359-371.

Grzywacz, J. G., \& Marks, N. F. (2000). Reconceptualizing the workfamily interface: An ecological perspective on the correlates of positive and negative spillover between work and family. Journal of Occupational Health Psychology, 5, 111-126.

Hobfoll, S. E. (1998). Stress, culture, and community: The psychology and physiology of stress. New York: Plenum Press.

Hockey, G. R. J. (1996). Energetical-control processes in the regulation of human performance. In W. Battmann \& S. Dutke (Eds.), Processes of the molar regulation of behavior (pp. 271-287). Berlin, Germany: Pabst Science Publishers.

Hofmann, D. A., \& Gavin, M. B. (1998). Centering decisions in hierarchical linear models: Implications for research in organizations. Journal of Management, 24, 623-641.

Houtman, I. L. D., \& Kompier, M. A. J. (1995). Risk factors and occupational risk groups for work stress in the Netherlands. In S. L. Sauter \& L. R. Murphy (Eds.), Organizational risk factors for job stress (pp. 209-225). Washington, DC: American Psychological Association.

Iso-Ahola, S. E. (1997). A psychological analysis of leisure and health. In. J. T. Haworth (Ed.), Work, leisure and well-being (pp. 131-144). London: Routledge.

Jackson, P. R., Wall, T. D., Martin, R., \& Davids, K. (1993). New measures of job control, cognitive demand, and production responsibility. Journal of Applied Psychology, 78, 753-762.

Jansen, N. W. H., Kant, I., \& van den Brandt, P. A. (2002). Need for recovery in the working population: Description and associations with fatigue and psychological distress. International Journal of Behavioral Medicine, 9, 322-340.

Jones, F., \& Fletcher, B. (1996). Taking work home: A study of daily fluctuations in work stressors, effects on moods and impacts on marital partners. Journal of Occupational and Organizational Psychology, 69, 89-106.

Kahn, R. L., \& Byosiere, P. (1992). Stress in organizations. In M. D. Dunnette \& L. M. Hough (Eds.), Handbook of industrial and organizational psychology (2nd ed., Vol. 3, pp. 571-650). Palo Alto, CA: Consulting Psychologists Press.

Karasek, R. A., \& Theorell, T. (1990). Healthy work: Stress, productivity, and the reconstruction of working life. New York: Basic Books.

Knardahl, S., \& Ursin, H. (1985). Sustained activation and the pathophysiology of hypertension and coronary heart disease. In J. Orlebeke, G. Mulder, \& L. Van Doornen (Eds.), Psychophysiology of cardiovascular control, models, methods and data (pp. 223-237). New York: Plenum Press.

Konradt, U., Schmook, R., \& Mälecke, M. (2000). Impacts of telework on individuals, organizations, and families. In C. L. Cooper \& I. T. Robertson (Eds.), International review of industrial and organizational psychology (Vol. 15, pp. 63-100). New York: Wiley.

Krull, J. L., \& MacKinnon, D. P. (1999). Multilevel mediation modeling in group-based intervention studies. Evaluation Review, 23, 418-444.

Krull, J. L., \& MacKinnon, D. P. (2001). Multilevel modeling of individual and group level mediated effects. Multivariate Behavioral Reserach, 36 , $249-277$.

Kuiper, J. I., van der Beek, A. J., \& Meijman, Th. F. (1998). Psychosomatic 
complaints and unwinding of sympathoadrenal activation after work. Stress Medicine, 14(7), 7-12.

Linden, W., Earle, T. L., Gerin, W., \& Christenfeld, N. (1997). Physiological stress reactivity and recovery: Conceptual siblings separated at birth? Journal of Psychosomatic Research, 42, 117-135.

Lounsbury, J. W., \& Hoopes, L. L. (1986). A vacation from work: Chances in work and nonwork outcomes. Journal of Applied Psychology, 71, 392-401.

Lundberg, U., Marberg, B., \& Frankenhauser, M. (1994). The total workload of male and female white collar workers as related to age, occupational level and number of children. Scandinavian Journal of Psychology, 35, 315-327.

MacKinnon, D. P., \& Dwyer, J. H. (1993). Estimating mediated effects in prevention studies. Evaluation Review, 17, 144-158.

Maslach, C., Schaufeli, W. B., \& Leiter, M. P. (2001). Job burnout. Annual Review of Psychology, 52, 397-422.

McLaney, M. A., \& Hurrell, J. J., Jr. (1988). Control, stress, and job satisfaction in Canadian nurses. Work and Stress, 2, 217-224.

Meijman, Th. F. (1991). Over Vermoeidheid [On fatigue]. Groningen, Germany: University of Groningen.

Meijman, Th. F., \& Mulder, G. (1998). Psychological aspects of workload. In P. J. D. Drenth \& H. Thierry (Eds.), Handbook of work and organizational psychology: Vol. 2. Work psychology (pp. 5-33). Hove, England: Psychology Press

Meijman, Th. F., Mulder, G., Van Dormolen, M., \& Cremer, R. (1992). Workload of driving examiners: A psychophysiological field study. In H. Kragt (Ed.), Enhancing industrial performances (pp. 245-260). London: Taylor \& Francis.

Michon, J. A. (1975). Time experience and memory processes. In J. T. Fraser \& N. Lawrence (Eds.), The study of time II (pp. 302-313). New York: Springer-Verlag.

Nitsch, J. R. (1976). Die Eigenzustandsskala (EZ-Skala)—Ein Verfahren zur hierarchisch-mehrdimensionalen Befindlichkeitsskalierung [State scale-An approach for the hierarchical-multidimensional scaling of mood]. In J. R. Nitsch \& I. Udris (Eds.), Beanspruchung im Sport (pp. 81-102). Bad Homburg, Germany: Limpert.

Pressman, M. R., \& Orr, W. C. (1997). Understanding sleep: The evaluation and treatment of sleep disorders. Washington, DC: American Psychological Association.

Rasbash, J., \& Woodhouse, G. (1996). MLn. London: University of London, Institute of Education.

Repetti, R. L. (1993). Short-term effects of occupational stressors on daily mood and health complaints. Health Psychology, 12, 125-131.

Rissler, A., \& Elgerot, A. (1978). Stress reactions during overtime at work. Longitudinal study of psychological reactions during and after work (Report No. 23). Stockholm, Sweden: University of Stockholm, Department of Psychology.

Roe, R. A., \& Zijlstra, F. R. H. (2000). Work pressure. Results of a conceptual and empirical analysis. In M. Vartiainen, F. Avallone, \& N. Anderson (Eds.), Innovative theories, tools and practices in $W \& O P s y$ chology (pp. 29-46). Göttingen, Germany: Hogrefe.

Saris, W. E. (Ed.). (1988). Variation in response behaviour-a source of measurement error in survey research. Amsterdam: Sociometric Research Foundation.

Sauter, S. L., Hurrell, J. J., \& Cooper, C. L. (1989). Job control and worker health. New York: Wiley.

Schiffman, N., \& Greist-Bousquet, S. (1992). The effect of task interruption and closure on perceived duration. Bulletin of the Psychonomic Society, 30, 9-11.

Semmer, N. (1984). Stressbezogene Tätigkeitsanalyse [Stress-related job analysis]. Weinheim, Germany: Beltz.

Semmer, N., Zapf, D., \& Dunckel, H. (1999). Instrument zur Stressbezogenen Tätigkeitsanalyse (ISTA) [Instrument for Stress-Oriented Analysis of Work]. In H. Dunckel (Ed.), Handbuch psychologischer Arbeit- sanalyseverfahren [Handbook of psychological work analysis instruments] (pp. 179-204). Zürich, Switzerland: Vdf Hochschulverlag an der ETH

Sluiter, J. K., de Croon, E. M., Meijman, T. F., \& Frings-Dresen, M. H. W. (2003). Need for recovery from work related fatigue and its role in the development and prediction of subjective health complaints. Occupational and Environmental Medicine, 60(Suppl. 1), i62-i70.

Sluiter, J. K., Frings-Dresen, M. H. W., van der Beek, A. J., \& Meijman, T. F. (2001). The relation between work-induced neuroendocrine reactivity and recovery, subjective need for recovery, and health status. Journal of Psychosomatic Research, 50, 29-37.

Sluiter, J. K., van der Beek, A. J., \& Frings-Dresen, M. H. W. (1999). The influence of work characteristics on the need for recovery and experienced health: A study on coach drivers. Ergonomics, 42, 573-583.

Snijders, T. A. B., \& Bosker, R. J. (1999). Multilevel analysis. An introduction to basic and advanced multilevel modeling. London: Sage.

Sonnentag, S. (2001). Work, recovery activities, and individual well-being: A diary study. Journal of Occupational Health Psychology, 6, 196-210.

Sonnentag, S. (2003). Recovery, work engagement, and proactive behavior: A new look at the interface between nonwork and work. Journal of Applied Psychology, 88, 518-528.

Sonnentag, S., \& Frese, M. (2003). Stress in organizations. In W. C. Borman, D. R. Ilgen, \& R. J. Klimoski (Eds.), Comprehensive handbook of psychology: Vol. 12. Industrial and organizational psychology (pp. 453-491). New York: Wiley.

Sonnentag, S., \& Jelden, S. (2005, April). The recovery paradox: Why we don't exercise after stressful days. Poster presented at the 20th annual conference of the Society for Industrial and Organizational Psychology, Los Angeles, CA.

Steptoe, A., Lundwall, K., \& Cropley, M. (2000). Gender, family structure and cardiovascular activity during the working day and evening. Social Science and Medicine, 50, 531-539.

Thayer, R. E., Newman, J. R., \& McClain, T. M. (1994). Self-regulation of mood: Strategies for changing a bad mood, raising energy, and reducing tension. Journal of Personality and Social Psychology, 67, 910-925.

Totterdell, P., \& Parkinson, B. (1999). Use and effectiveness of selfregulation strategies for improving mood in a group of trainee teachers. Journal of Occupational Health Psychology, 4, 219-232.

Totterdell, P., Spelten, E., Smith, L., Barton, J., \& Folkard, S. (1995). Recovery from work shifts: How long does it take? Journal of Applied Psychology, 80, 43-57.

Van Veldhoven, M., \& Meijman, T. (1994). Het meten van psychosociale arbeids-belasting met een vragenlijst: De Vragenlijst Beleving en Beoordeling van de Arbeid (VBBA) [Measuring psychosocial workload with a questionnaire]. Tijdschrift voor Bedrijfs- en Verzekeringsgeneeskunde, 2, 229-230.

Vercoulen, J. H. M. M., Swanink, C. M. A., Fennis, J. F. M., Galama, J. M. D., Van der Meer, J. W. M., \& Bleijenberg, G. (1994). Dimensional assessment of chronic fatigue syndrome. Journal of Psychosomatic Research, 38, 383-392.

Verwey, W. B., \& Veltman, H. A. (1996). Detecting short periods of elevated workload: A comparison of nine workload assessment techniques. Journal of Experimental Psychology: Applied, 2, 270-285.

Waldron, I., Weiss, C. C., \& Hughes, M. E. (1998). Interacting effects of multiple roles on women's health. Journal of Health and Social Behavior, 39, 216-236.

Watson, D., Clark, L. A., \& Tellegen, A. (1988). Development and validation of brief measures of positive and negative affect: The PANAS scales. Journal of Personality and Social Psychology, 54, 1063-1070.

Westman, M., \& Eden, D. (1997). Effects of a respite from work on burnout: Vacation relief and fade-out. Journal of Applied Psychology, 82, 516-527. 
Westman, M., \& Etzion, D. (2001). The impact of vacation and job stress on burnout and absenteeism. Psychology and Health, 16, 595-606.

Zapf, D. (1993). Stress-oriented analysis of computerized office work. European Work and Organizational Psychologist, 3, 85-100.

Zijlstra, F. R. H. (1993). Efficiency in work behaviour: A design approach for modern tools. Delft, the Netherlands: Delft University Press.

Zijlstra, F. R. H. (1996). Effort as energy regulation. In W. Battmann \& S. Dutke (Eds.). Processes of the molar regulation of behavior (pp. 219235). Berlin, Germany: Pabst Science Publishers.

Zijlstra, F. R. H., Schalk, M. J. D., \& Roe, R. A. (1996). Veranderingen in de Arbeid. Consequenties voor Werkenden [Changes in the domain of work: Consequences for working people]. Tijdschrift voor Arbeidsvraagstukken, 12, 251-263.

Zohar, D. (1999). When things go wrong: The effect of daily work hassles on effort, exertion and negative mood. Journal of Occupational and Organizational Psychology, 72, 265-283.

Received April 1, 2003 Revision received March 1, 2004 Accepted February 17, 2005 